\title{
The association between income inequality and adult mental health at the subnational level-a systematic review
}

\author{
Marc S. Tibber ${ }^{1}$ (1) $\cdot$ Fahreen Walji $^{1} \cdot$ James B. Kirkbride ${ }^{2} \cdot$ Vyv Huddy $^{3}$
}

Received: 18 March 2021 / Accepted: 30 July 2021 / Published online: 13 August 2021

(c) The Author(s) 2021

\begin{abstract}
Purpose A systematic review was undertaken to determine whether research supports: (i) an association between income inequality and adult mental health when measured at the subnational level, and if so, (ii) in a way that supports the Income Inequality Hypothesis (i.e. between higher inequality and poorer mental health) or the Mixed Neighbourhood Hypothesis (higher inequality and better mental health).

Methods Systematic searches of PsycINFO, Medline and Web of Science databases were undertaken from database inception to September 2020. Included studies appeared in English-language, peer-reviewed journals and incorporated measure/s of objective income inequality and adult mental illness. Papers were excluded if they focused on highly specialised population samples. Study quality was assessed using a custom-developed tool and data synthesised using the vote-count method. Results Forty-two studies met criteria for inclusion representing nearly eight million participants and more than 110,000 geographical units. Of these, 54.76\% supported the Income Inequality Hypothesis and 11.9\% supported the Mixed Neighbourhood Hypothesis. This held for highest quality studies and after controlling for absolute deprivation. The results were consistent across mental health conditions, size of geographical units, and held for low/middle and high income countries. Conclusions A number of limitations in the literature were identified, including a lack of appropriate (multi-level) analyses and modelling of relevant confounders (deprivation) in many studies. Nonetheless, the findings suggest that area-level income inequality is associated with poorer mental health, and provides support for the introduction of social, economic and public health policies that ameliorate the deleterious effects of income inequality.
\end{abstract}

Clinical registration number PROSPERO 2020 CRD42020181507.

Keywords Inequality $\cdot$ Deprivation $\cdot$ Poverty $\cdot$ Social determinants $\cdot$ Mental health

\section{Introduction}

Mental disorders are the leading cause of years lived with disability worldwide [1]. Whilst this has led to calls for greater investment in psychological therapies [2], of which the UK's improving access to psychological therapies (IAPT) scheme is a prime example [3], such an approach, which (arguably) locates the problem as well as the solution

Marc S. Tibber

m.tibber@ucl.ac.uk

1 Department of Clinical, Educational and Health Psychology, UCL, London, UK

2 PsyLife Group, Division of Psychiatry, UCL, London, UK

3 Clinical and Applied Psychology Unit, Department of Psychology, University of Sheffield, Sheffield, UK in the individual, has had its detractors. Thus, many have proposed that such an approach fails to take into consideration the socioeconomic contexts in which mental illness, and distress more generally, occurs, and consequently, removes the onus on governments for broader social and economic reform [4-6].

With respect to the existing evidence-base, the association between income and health is well established [7]. For example, life expectancy increases as a function of gross national product (GNP), though the effects typically saturate at higher levels of GNP $[8,9]$. Whilst there are less data on mental health, there is evidence to suggest that mental health and wellbeing show a similar asymptotic relationship with GNP between nations [10-12]. One interpretation of these findings is that in poorer countries, income-and specifically a minimum level of income-is directly linked to health outcomes, since poverty limits access to basic needs 
such as food and clean water, i.e. poverty is associated with material deprivation. In contrast, in countries above a certain threshold of wealth, these factors become less important for a larger majority of the population, as basic needs are satisfied.

Looking at data within a country, e.g. comparisons across states or counties, income similarly predicts physical [13] and mental health outcomes [14-16], but unlike crossnational comparisons, the effects do not seemingly saturate at higher incomes. One explanation is that whilst income is an index of access to basic amenities in comparisons across countries, within a country income becomes an indicator of social position or socioeconomic status (SES). This is important, because a large body of research has shown that SES is inversely related to unhealthy behaviours such as smoking, physical inactivity and unhealthy eating [17].

According to the Income Inequality Hypothesis (IIH) [18], it is not just socioeconomic position per se that affects health, but socioeconomic position relative to others around you, namely inequality, i.e. the variance in incomes (or some related index of poverty or wealth) within a defined region. To characterise levels of objective inequality within a region several measures have been developed, including decile ratios, the Robin Hood index, and Gini coefficient, all of which correlate highly with one another [19]. The Gini coefficient is the most commonly used, and describes the extent to which the distribution of incomes in a region deviates from perfect equality, with high scores indicating high variance. In Wilkinson and Pickett's book, 'The Spirit Level' [11], the authors popularised the IIH, describing how the Gini coefficient positively predicts an aggregate index of health and social problems, as well as related indices such as obesity [20], life expectancy [21], incarceration, homicide rates, education and levels of childhood conflict [22, 23], both in cross-country comparisons as well as subnational comparisons between US states. Whilst a number of criticisms have been raised against Wilkinson and colleagues' analyses [24-26], the principle finding of an association between higher inequality and poorer physical health and social outcomes, though small, has since been confirmed [27-30].

With respect to the possible mechanisms underlying the association between income inequality and health, three main theories have been proposed [31,32]. According to the Social Capital Hypothesis $(\mathrm{SCH})$ when individuals or groups of individuals differ greatly in their incomes (i.e. conditions of high inequality), they are less likely to trust one another, or to interact and form cohesive social networks [33], which may be inherently stressogenic [34]. Such conditions are also less likely to engender acts of reciprocity and practical support [35]. In contrast, the Status Anxiety Hypothesis (SAH) proposes that income inequality leads to greater social comparison between the rich and poor, which may also be stressful and detrimental to health [36, 37]. Finally, the Neomaterialist Hypothesis (NMH), posits that when levels of inequality are high, less investment is made into public infrastructure and welfare services [38-40], e.g. gyms, parks and hospitals, which in turn, leads to poorer health outcomes [41].

Others have proposed an association between health and inequality that runs contrary to the IIH, i.e. an association between higher inequality and better health. According to the Mixed Neighbourhood hypothesis (MNH) [42-44], whilst neighbourhoods of homogeneous poverty, i.e. areas of high deprivation but low inequality, may become mired by a lack of social opportunities and cultures of crime, substance use and joblessness, the MNH proposes that these effects can be ameliorated by integration with individuals of a higher SES, i.e. areas of high deprivation but high inequality also. On a purely pragmatic level, poorer members of the community may benefit from the increased investment in local infrastructure and resources that such heterogeneity brings. In some countries this has led to the adoption of mixedincome housing development schemes, e.g. the HOPE VI project [45], although this is a highly controversial approach, which some have argued is founded on insufficient evidence [46-48].

Despite growing interest, there has been less research into the association between inequality and mental health than there has into the association with physical health [49]. Nonetheless, several systematic reviews of relevance have been undertaken. Burns and colleagues [50] undertook a systematic review of schizophrenia, and found that across data from 26 countries, there was a higher incidence rate of the condition in higher income countries $(\beta=1.02 ; Z=2.28$; $p=0.02 ; 95 \% \mathrm{CI}=1.00,1.03)$. In a systematic review and meta-analysis of depression [51], from 26 papers (of which 12 were included in the meta-analysis), the authors reported a greater risk of depression in populations with higher inequality $(\mathrm{RR}=1.19,95 \% \mathrm{CI}=1.07-1.31)$.

Only one review paper to date [52], however, has attempted to synthesise the literature on the association between inequality and mental health across different presentations. In their paper, the authors undertook a systematic review of 27 papers and a meta-analysis of nine studies, and concluded that there was a weak association between higher income inequality and any mental health difficulty (pooled Cohen's $d=0.06,95 \% \mathrm{CI}=0.01-0.11$ ). However, in defining their search terms they included only broad definitions of mental health problems rather than specific diagnostic categories. Consequently, a number of studies of relevance may have been missed, and biases may have been introduced with respect to study selection. In addition, they did not assess the impact on their findings of including only studies that had controlled for absolute deprivation. However, without controlling for absolute deprivation, any reported effects of 
inequality may be driven by this factor rather than inequality per se [53, 54].

To address these limitations, we undertook a systematic review of the association between inequality and mental health using a comprehensive set of search terms that included specific as well as broad definitions of mental health (and inequality), thereby ensuring good coverage. To disentangle the potential confounding effects of $a b s o$ lute deprivation in any studies, we also explored the extent to which any documented patterns persisted in a subset of papers that controlled for deprivation at either the individual or area level (or both).

In addition, we explored a number of more specific predictions that have been made in relation to the IIH. First, that the association between inequality and health is not restricted to the poor, but is instead present in the rich also, i.e. the effect does not interact with absolute deprivation [11]. Second, that the effects of IIH do not hold across different geographical scales. Thus, in trying to make sense of the literature, Pickett and Wilkinson $[55,56]$ have proposed that the effects of inequality become weaker-or possibly do not even operate-at smaller scales, e.g. in comparisons between geographical areas below the level of US states, for example. Finally, we include only studies that describe analyses undertaken at the subnational level, e.g. comparisons across neighbourhoods or states rather than across countries, since first, as noted, socioeconomic processes may function differently in cross-national comparisons, and secondly, because this is the level at which mental health services are typically commissioned, designed and delivered, and political decisions are made.

\section{Methods}

This review represents an update of an unpublished thesis [57] prospectively registered with PROSPERO before the search was updated (CRD42020181507) [58]. The study is reported according to PRISMA guidelines [59]. A metaanalytic approach was not adopted since aggregation of effect sizes is inappropriate when studies differ markedly with respect to sample characteristics, outcome variables, methodologies and analytic approaches [60-62]. Instead, we conducted a narrative review, searching for broad patterns of support for opposing hypotheses (the IIH and $\mathrm{MNH}$ ) coupled with a vote-count approach [56, 63]. All studies were screened and coded independently by MT and FW. Findings were then reviewed together after each sequential step and any discrepancies discussed and resolved, with further input sought from JK where needed.

\section{Search strategy}

Studies were identified using a search of PsycINFO, Medline and Web of Science databases from database inception to the 2nd September, 2020, with no restriction on studies that could be included within this temporal window. A comprehensive set of search terms were based on the two key concepts of 'income inequality' (11 terms) and 'mental health' (52 terms); see Supplementary Information 1.

\section{Screening and selection}

All records were screened in two phases (see Fig. 1). First, the title and abstract were screened and methods section reviewed for basic relevance including a focus on mental health and objective inequality. Second, all remaining articles were read and relevant studies identified according to the following inclusion criteria: (i) included quantitative data; (ii) included a measure of mental illness incidence, prevalence or symptom severity, defined using a diagnostic tool, screening instrument or symptom scale; (iii) included an objective measure of income inequality, derived at the subnational level; (iv) focused on adult mental health ( $\geq 18$ years); (v) written in English; and (vi) published in peer-reviewed journals. Studies were excluded: (i) if the measure of inequality was based on subjective inequality; (ii) if the focus was on life satisfaction, health-care use, neurodevelopmental disorders, learning disabilities, degenerative diseases or behaviour, e.g. suicide or substance use; (iv) if the sample population was based on a highly specialised population sample, e.g. HIV + prisoners [64].

\section{Data extraction}

Remaining studies were coded for key measures to facilitate synthesis of findings and assessment of study quality (see Table 1). These included: the scale of the geographical region of interest, mean population size of the region of interest, data sample size (at individual and higher-order level), the type of analyses undertaken, predictors and covariates included in analyses, the significance of any findings at an alpha criterion level of 0.05 , as well as an index of study quality (see Supplementary Information 2). Further information about studies is also presented in Supplementary Information 3. Where data were not specified in a given study, this information was sought from original sources, e.g. government reports and national statistics, requested directly from the study's authors, and where not available coded 'NA'. 
Fig. 1 Study inclusion flow diagram. Flow diagram showing sequence by which studies were identified, screened and reviewed

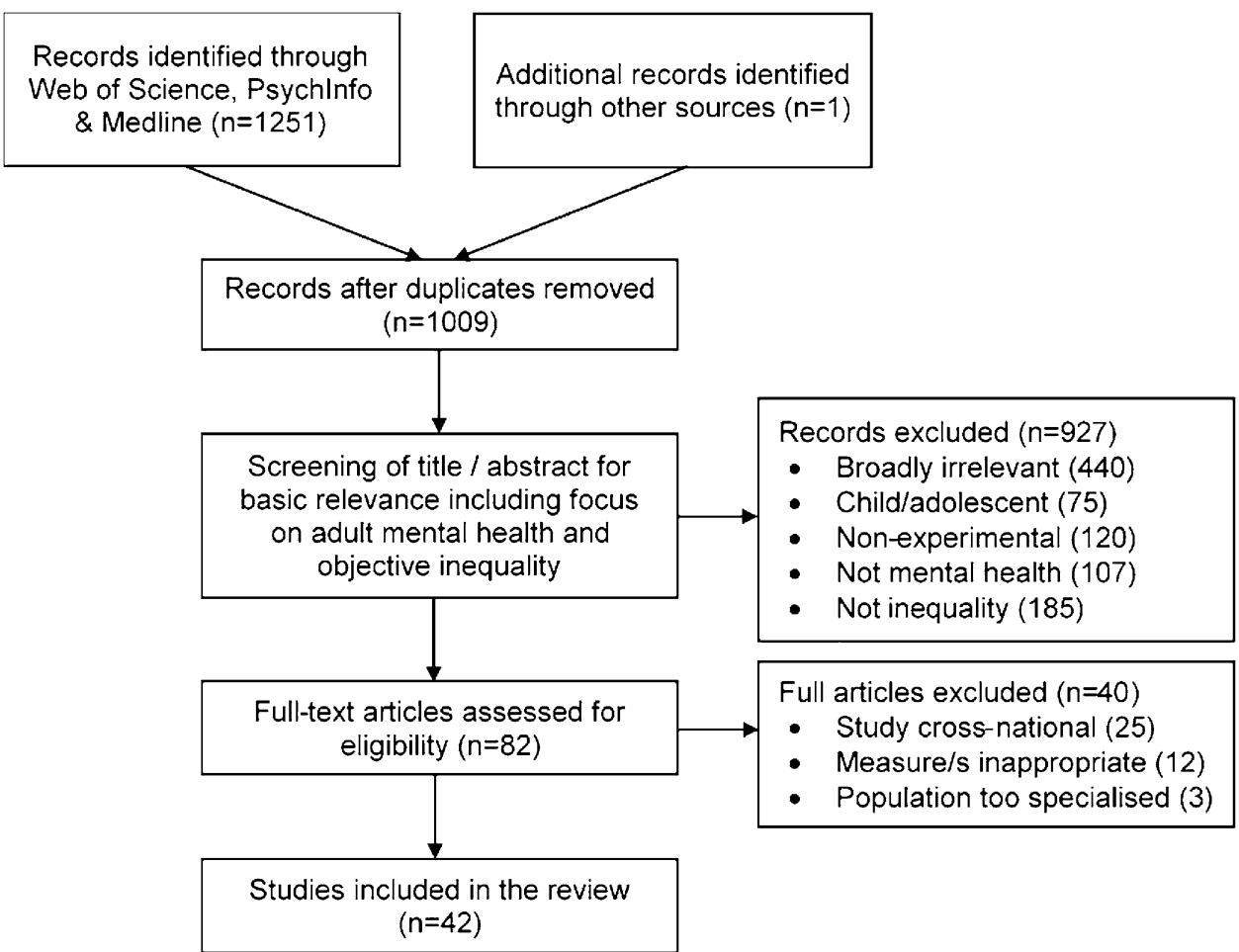

\section{Quality assessment}

Following the approach of Uphoff and colleagues [65], studies were scored for quality rather than risk of bias, as appropriate for a critical appraisal of large-scale cross-sectional and/or ecological data. The following criteria were used to create a Quality Index (Qi): (i) validity of key measures, (ii) sample size, (iii) inclusion of appropriate confounder variables, and (iv) optimal statistical analyses. Items (i) and (ii) were taken directly from Uphoff and colleagues [65], and (iii) and (iv) were custom-developed to afford a more stringent assessment of quality in line with the research question; thus, multi-level analyses that control for absolute deprivation were deemed necessary for a convincing association to be demonstrated between inequality and mental health. See Supplementary Information 2 for further details.

\section{Data synthesis}

A vote-count approach was used to identify the proportion of studies that were consistent with: (a) the IIH, (b) the MNH, or (c) neither (i.e. no association between inequality and mental health). Note: we use the term 'consistent with' since without an established direction of causality and elucidation of mediating mechanisms, associations between inequality and mental health do not definitively prove the IIH or the MNH. Following Wilkinson and Pickett's [56], supportive categories were further broken down into sub-categories of 'wholly supportive' (where only significant associations were found in the defined direction), and 'partially supportive' (where some significant association in the defined direction and some null findings were reported). Missing data were excluded from syntheses rather than assumptions being made.

In addition, we undertook several 'sub-analyses', with the same vote-count approach implemented on a subset of studies. First, to assess the scale invariance of any reported effects, findings were explored at different geographical scales. Since the scale at which to stratify studies is relatively arbitrary, we took two principled approaches. Data were stratified according to mean population size of the geographical region of interest, with strata $(<45,000, \geq 45,000, \geq 4$ million) defined post hoc to generate approximately equal sized groups. Data were also stratified following a system used previously [56], with studies identified as focusing on regions of interest that corresponded broadly to: (i) states, regions and cities, and (ii) counties, tracts and parishes (Table 2). These corresponded to studies with regions of interest with mean population sizes that ranged from 1500-190,000 and 290,000-6 million.

Second, to determine whether study quality introduced any bias in findings, findings were also explored for higher quality studies only, i.e. those scoring four on the quality index (Qi). Third, to test for the potentially confounding role of absolute deprivation, findings were explored in a subset of studies for which deprivation was controlled at the lower level (e.g. individual or household), higher level (e.g. state or county), and at both levels. Fourth, to determine whether 


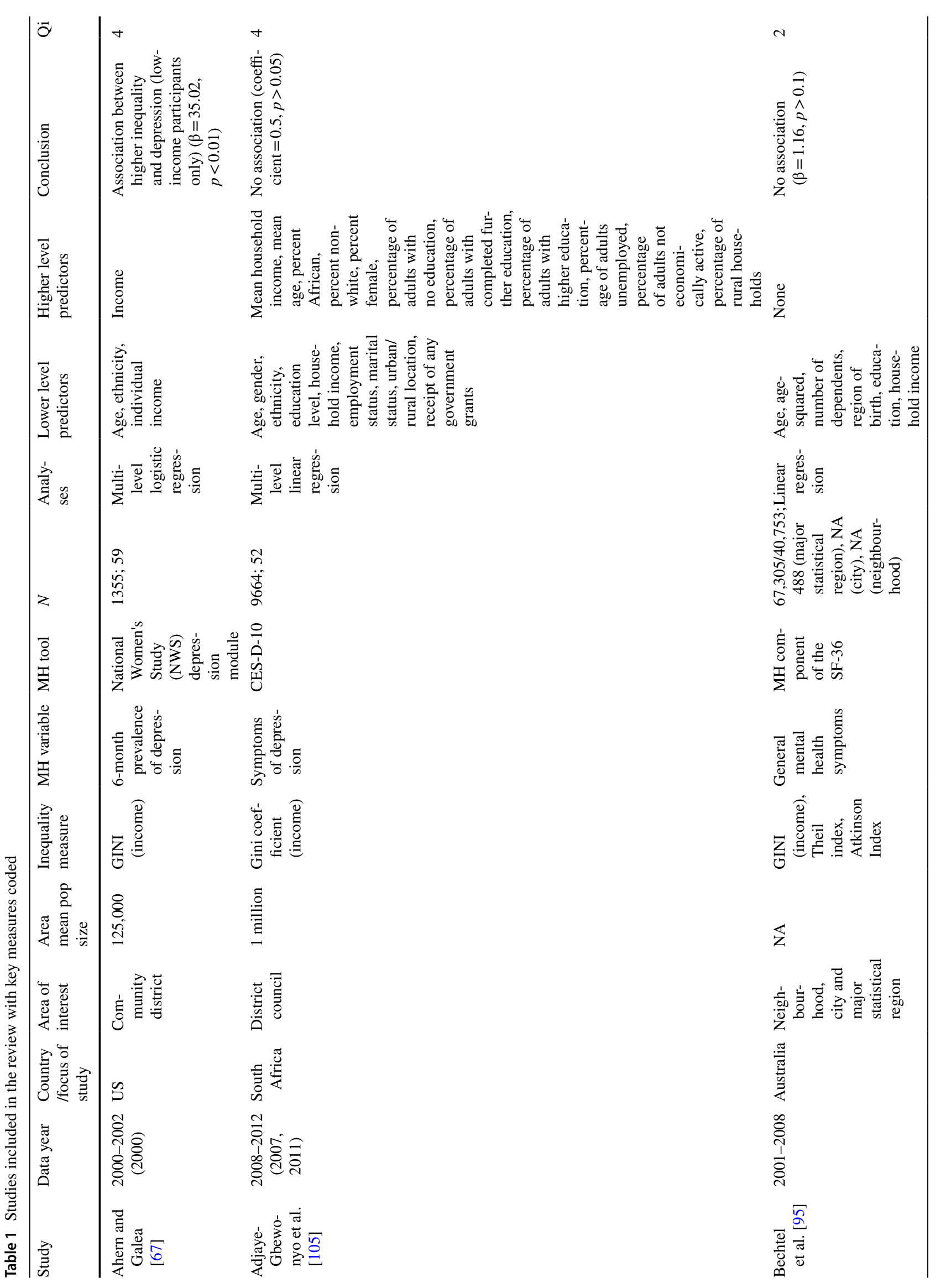




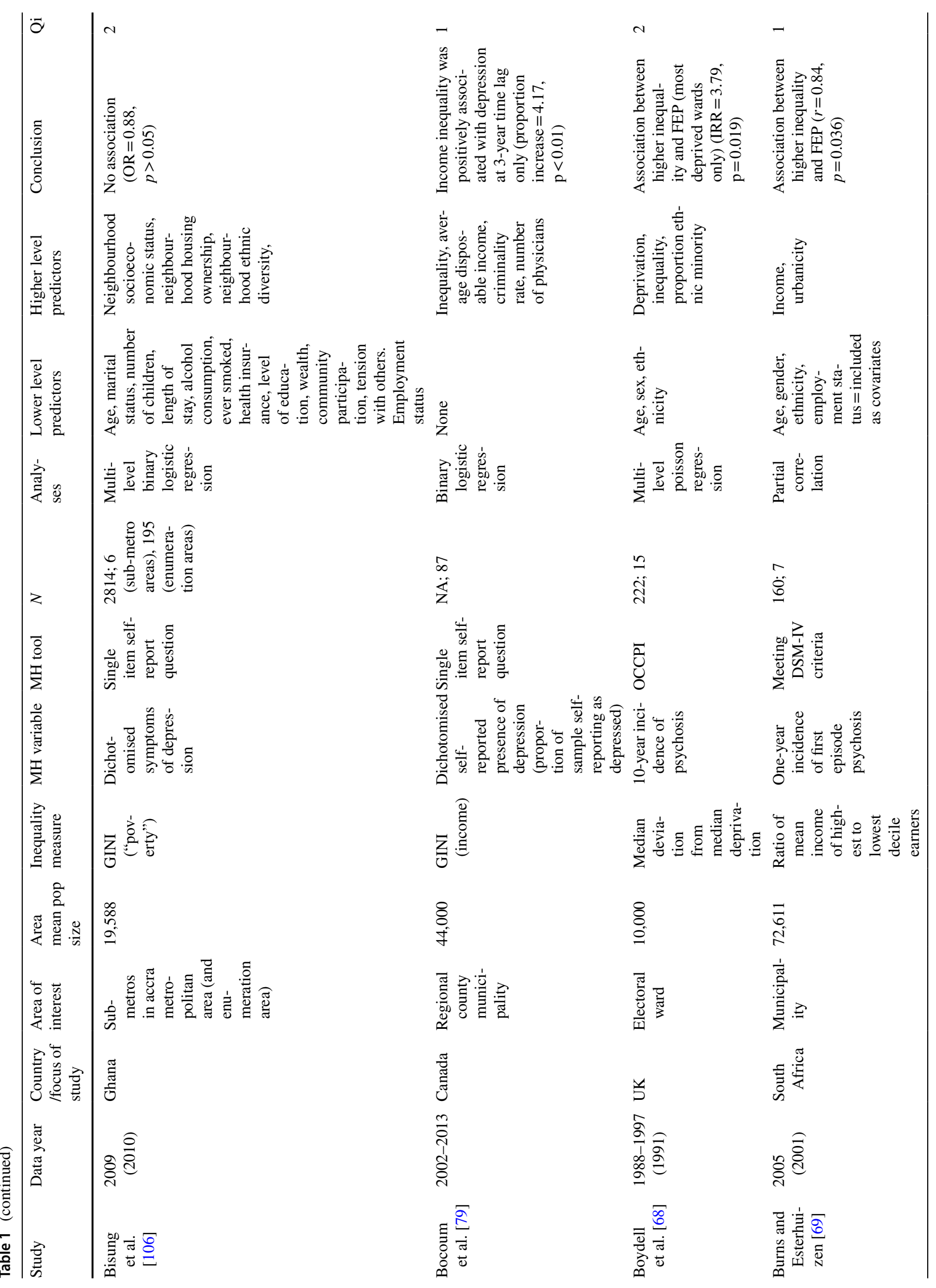




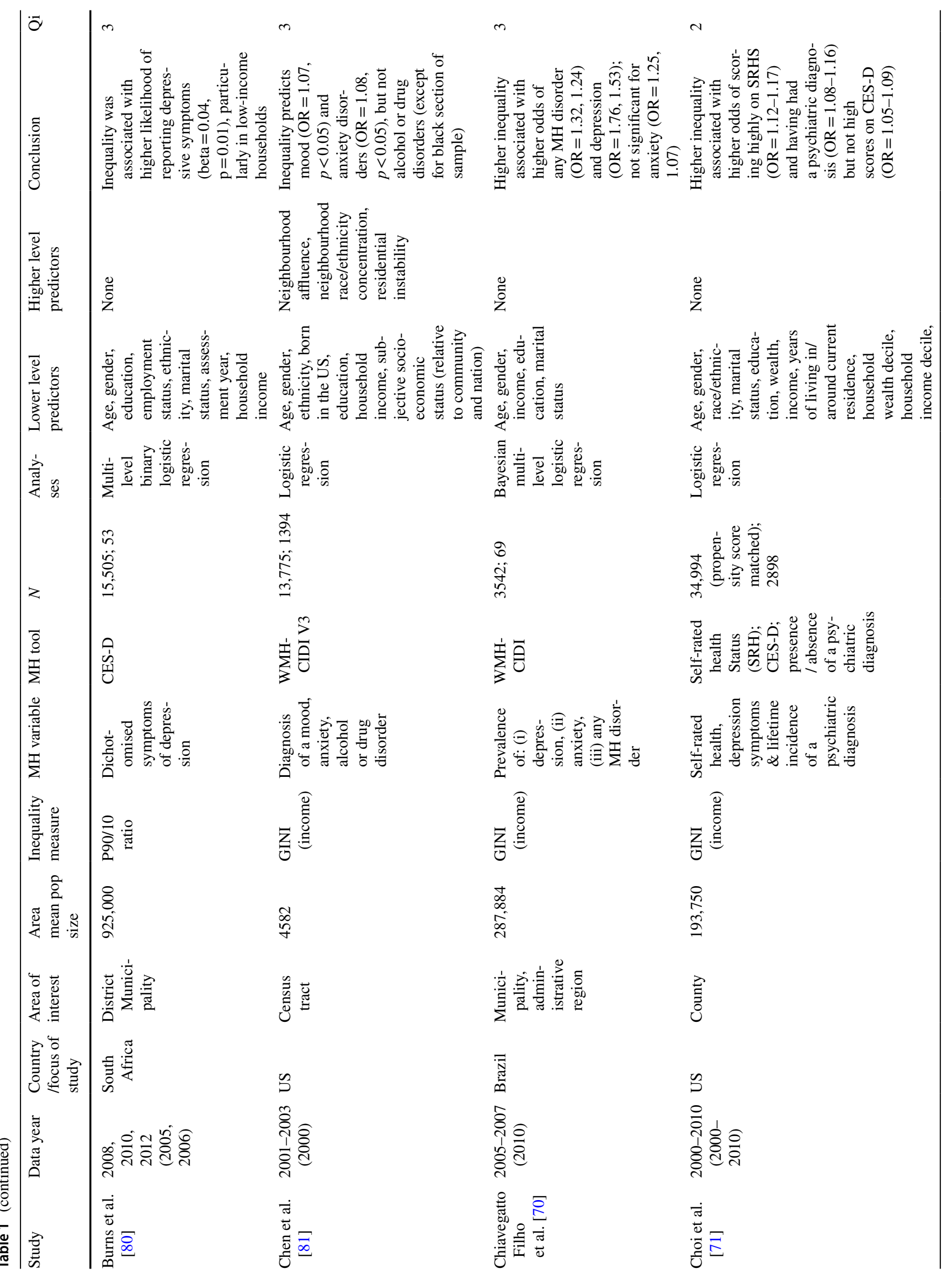




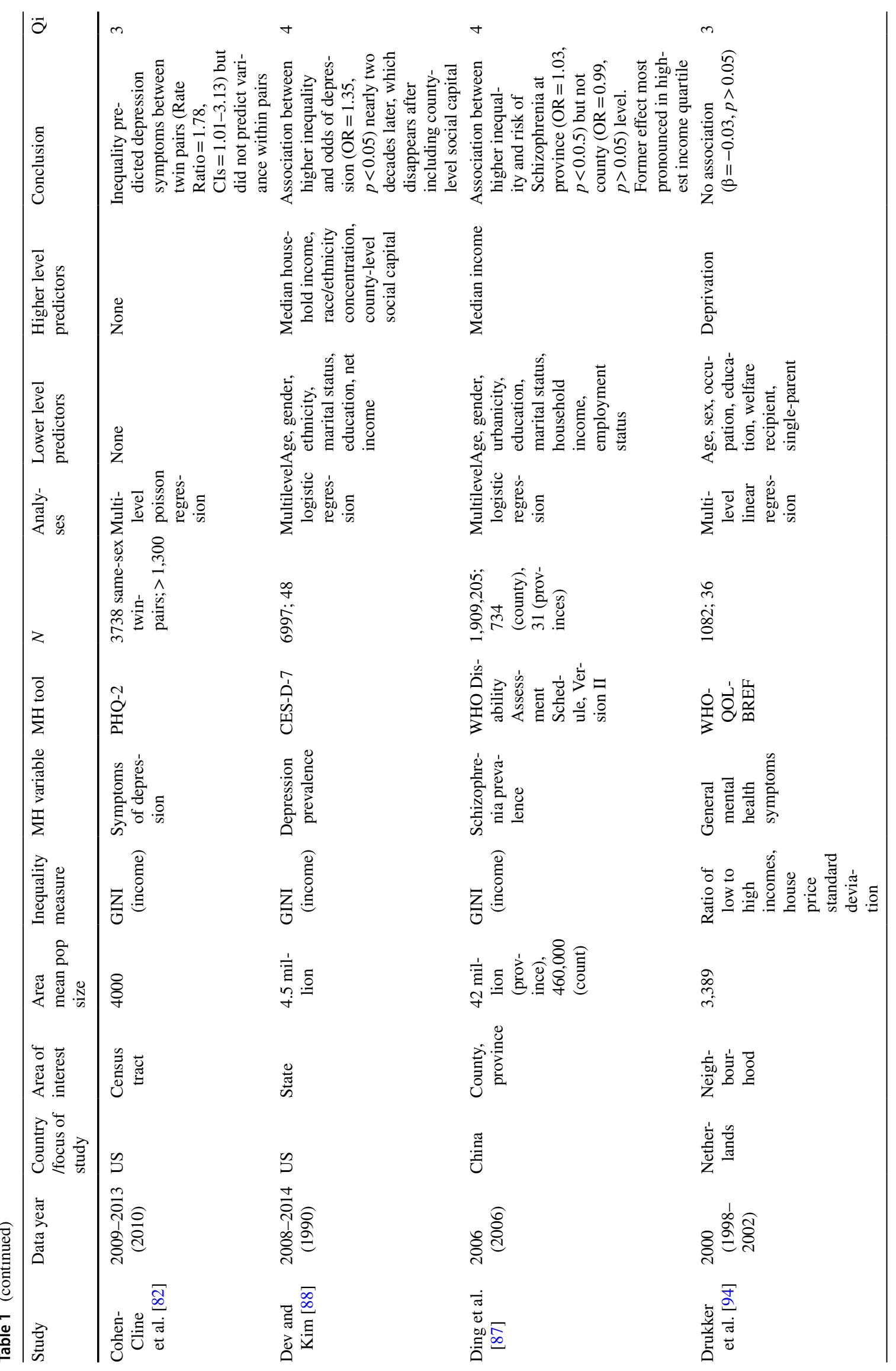


Social Psychiatry and Psychiatric Epidemiology (2022) 57:1-24

9

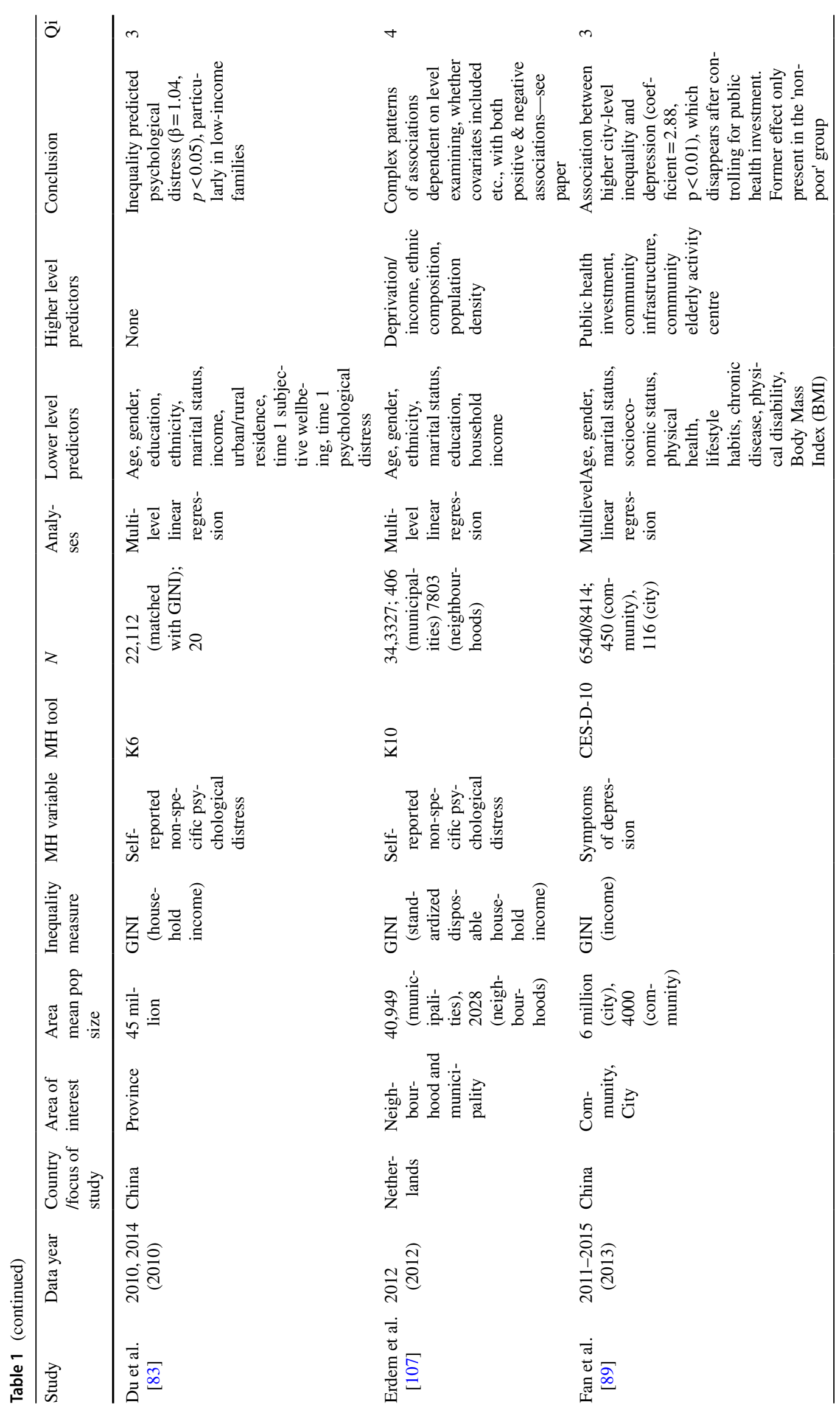

算 Springer 


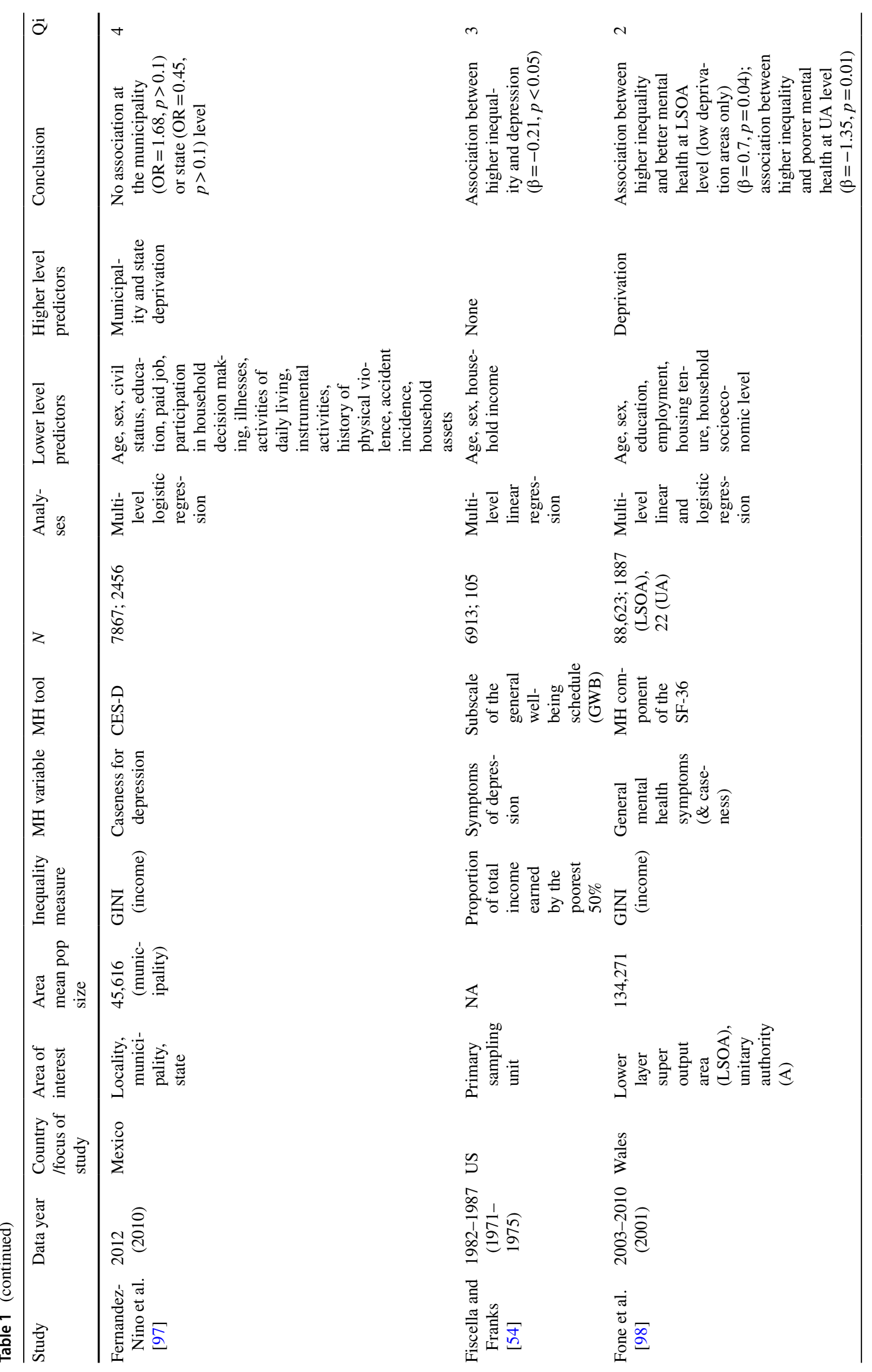




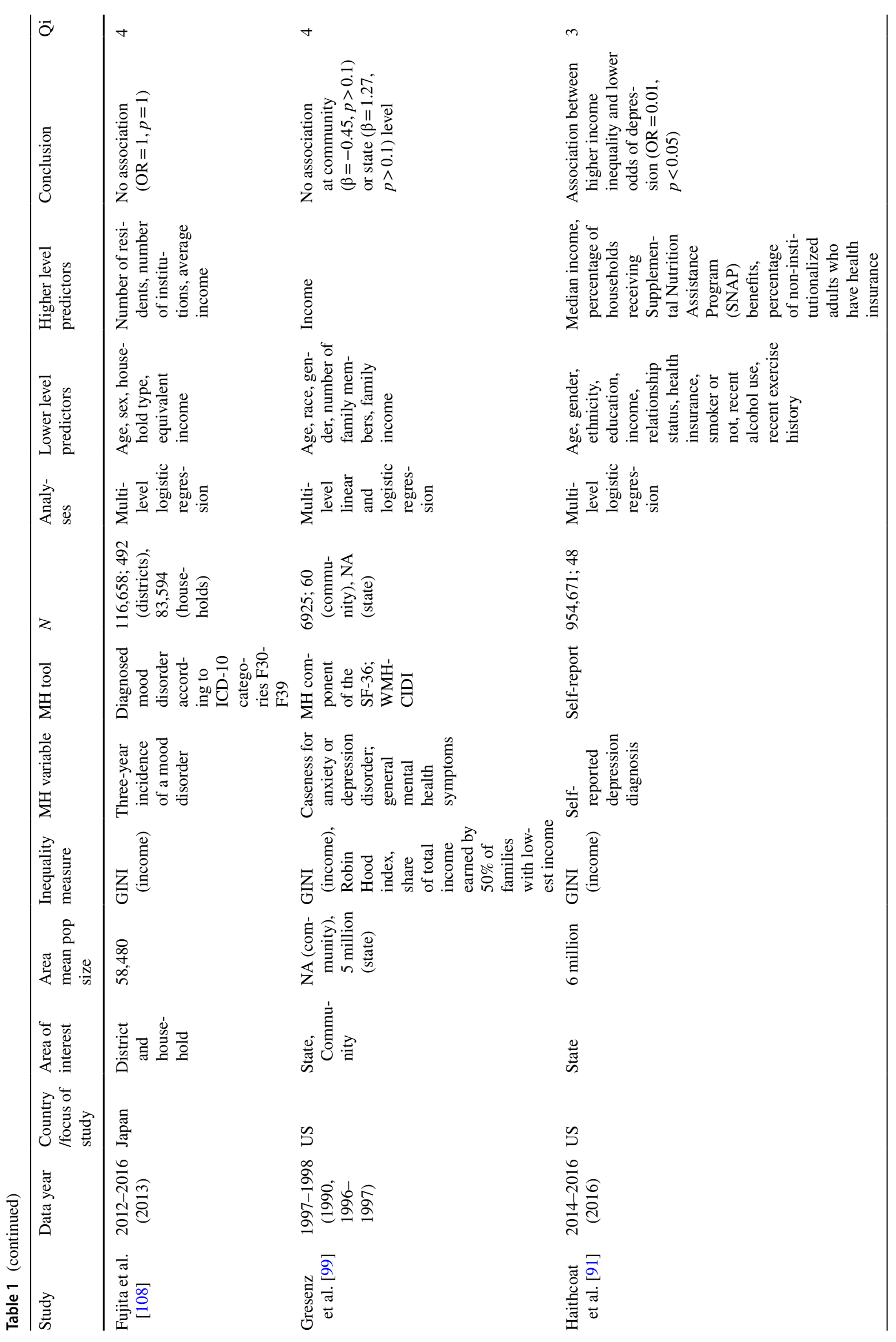




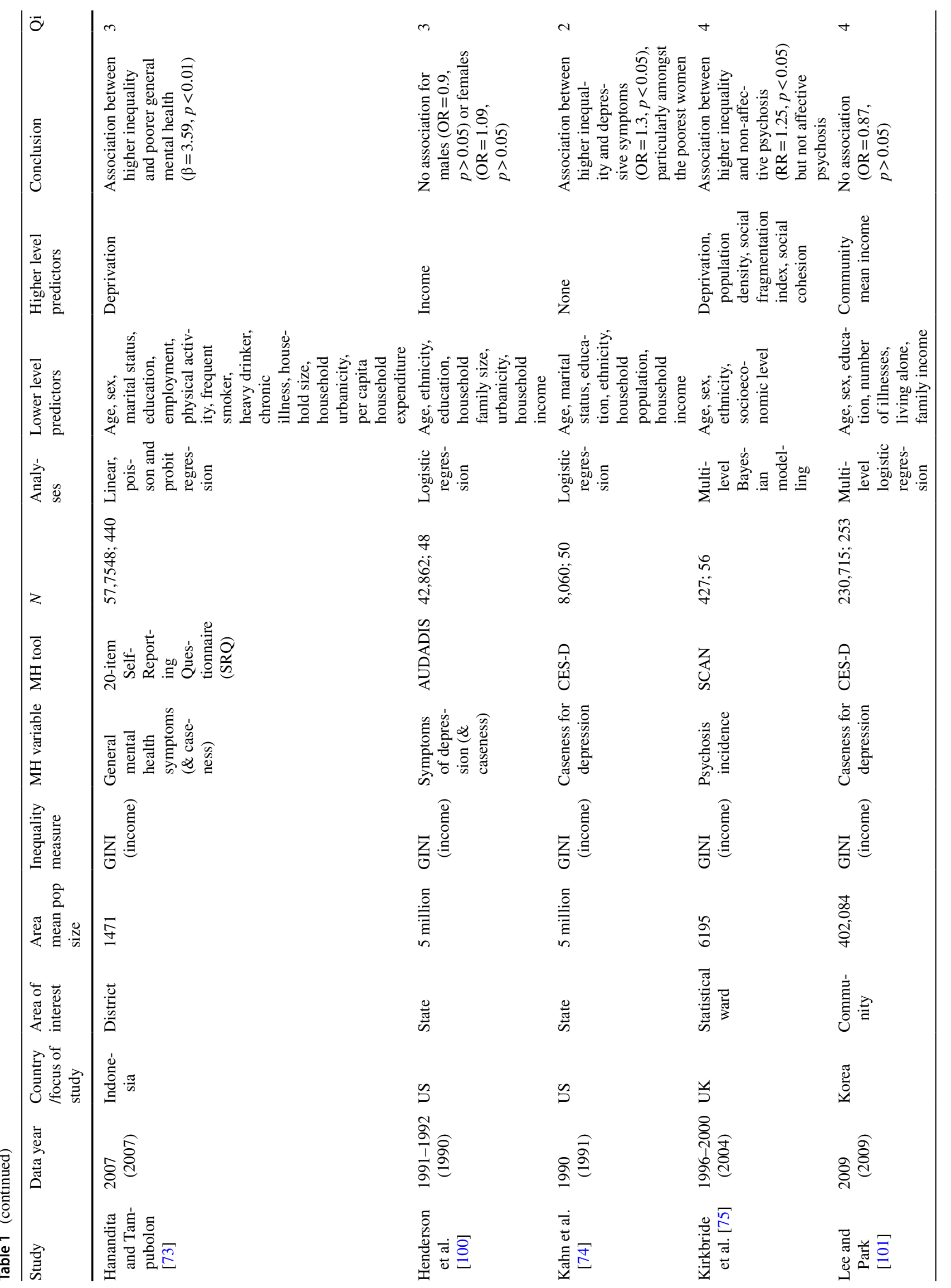




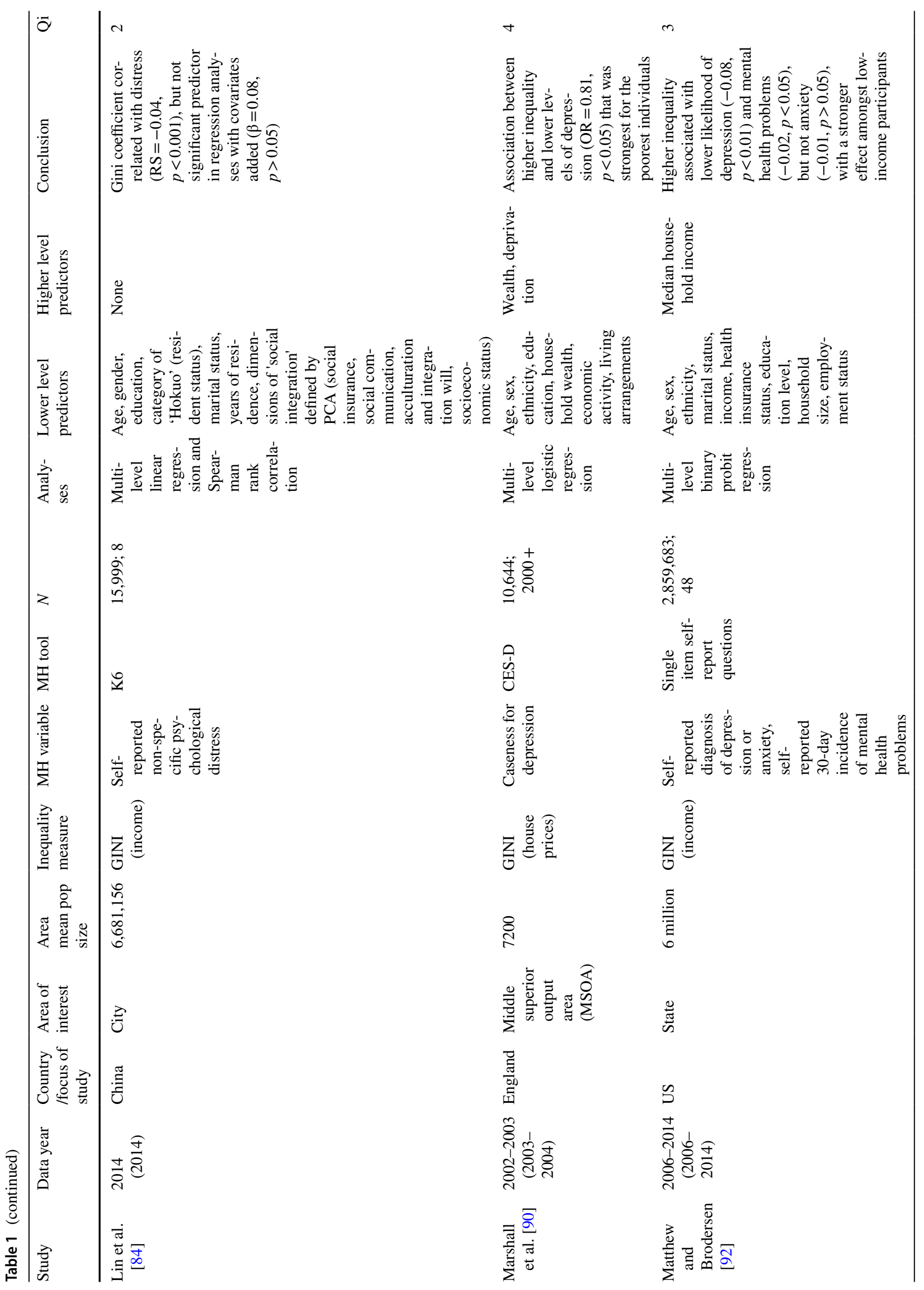




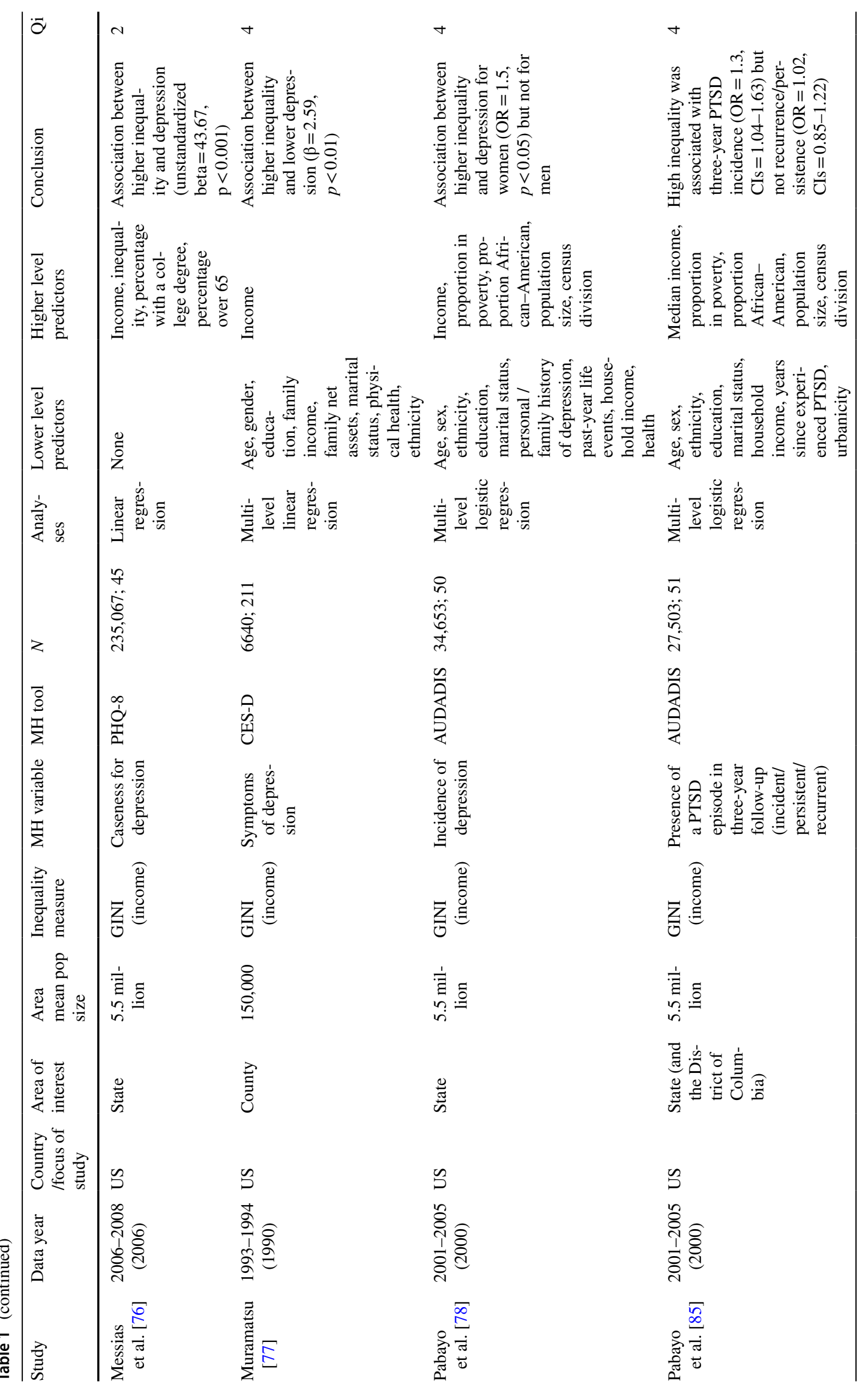




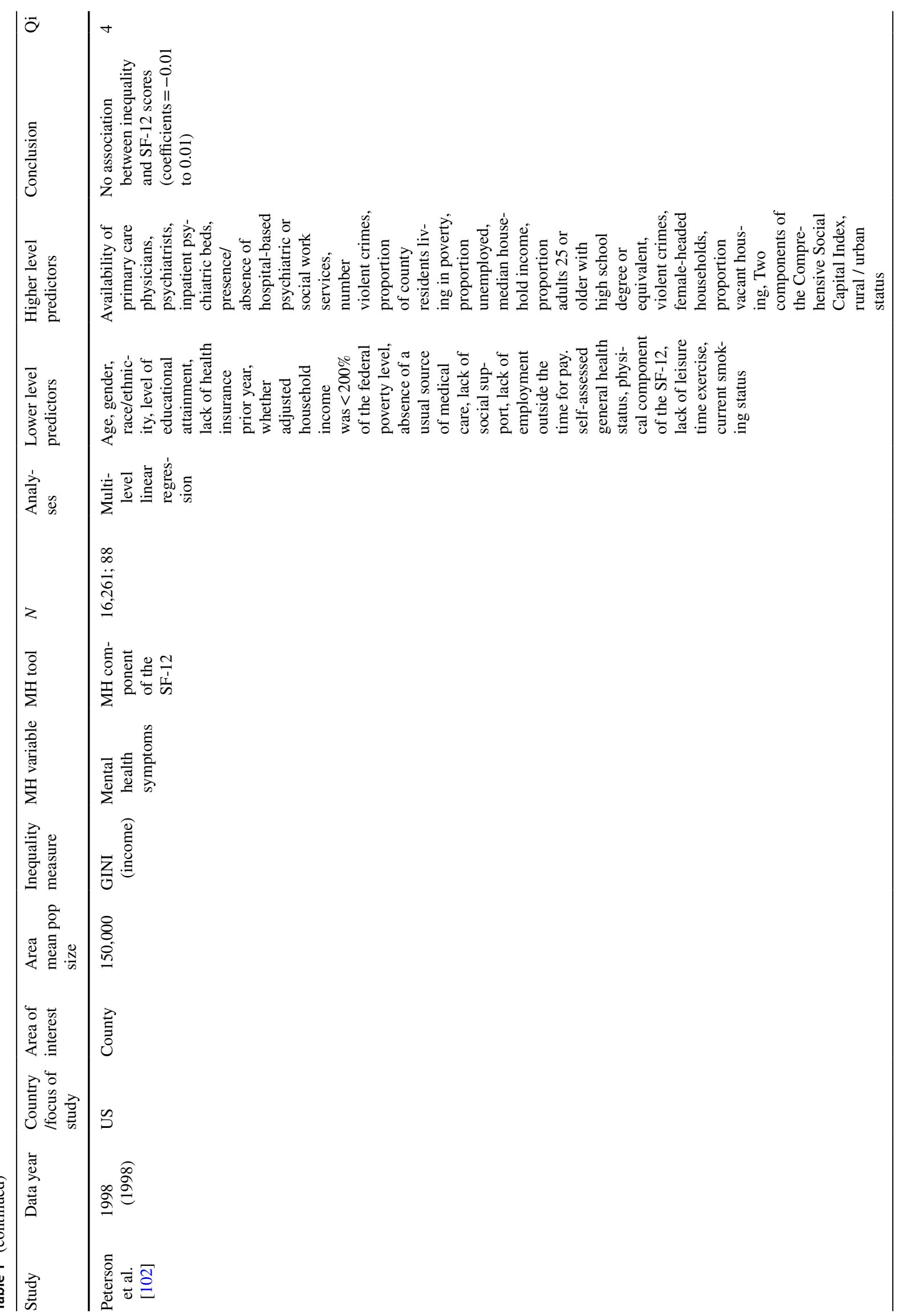




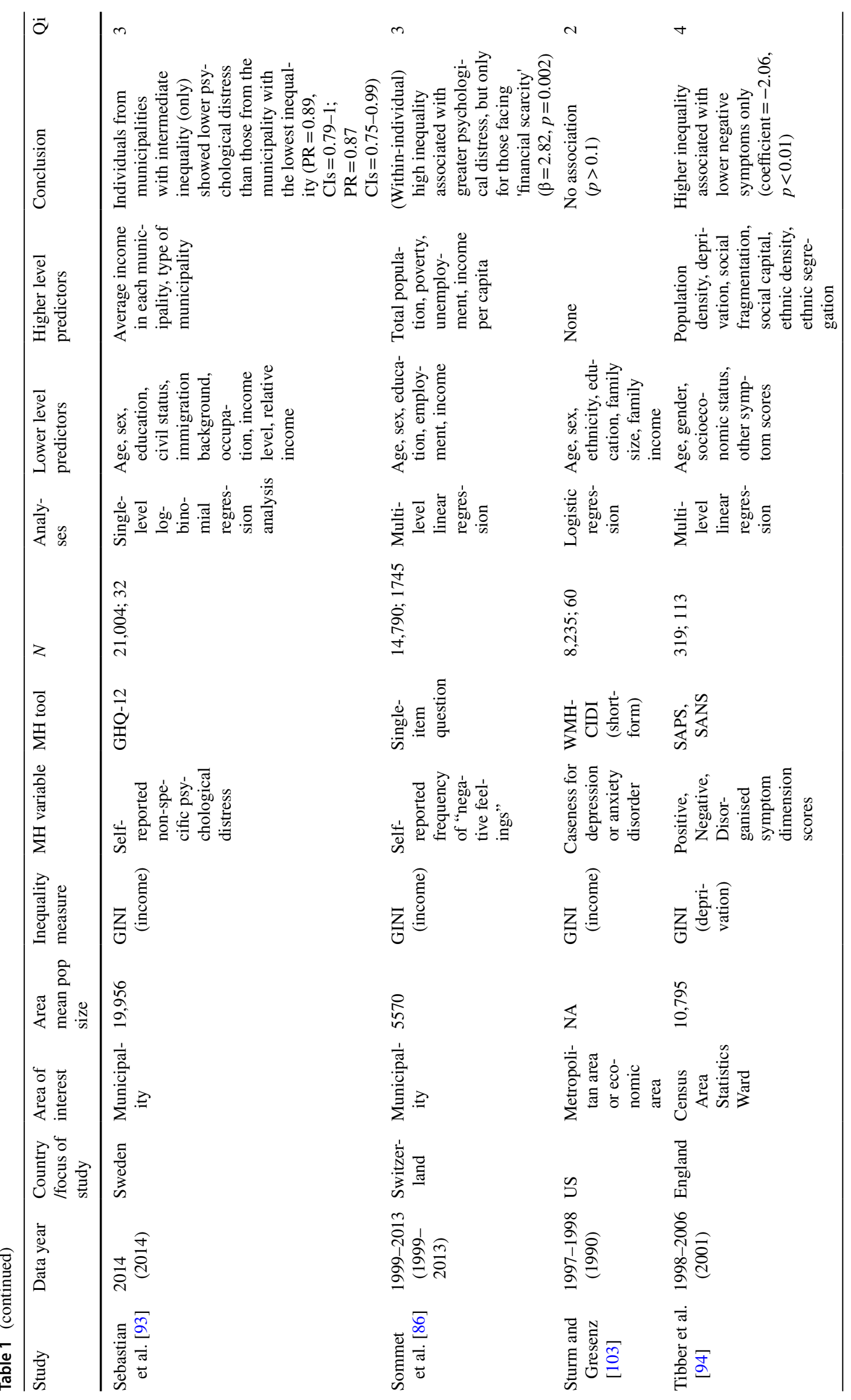




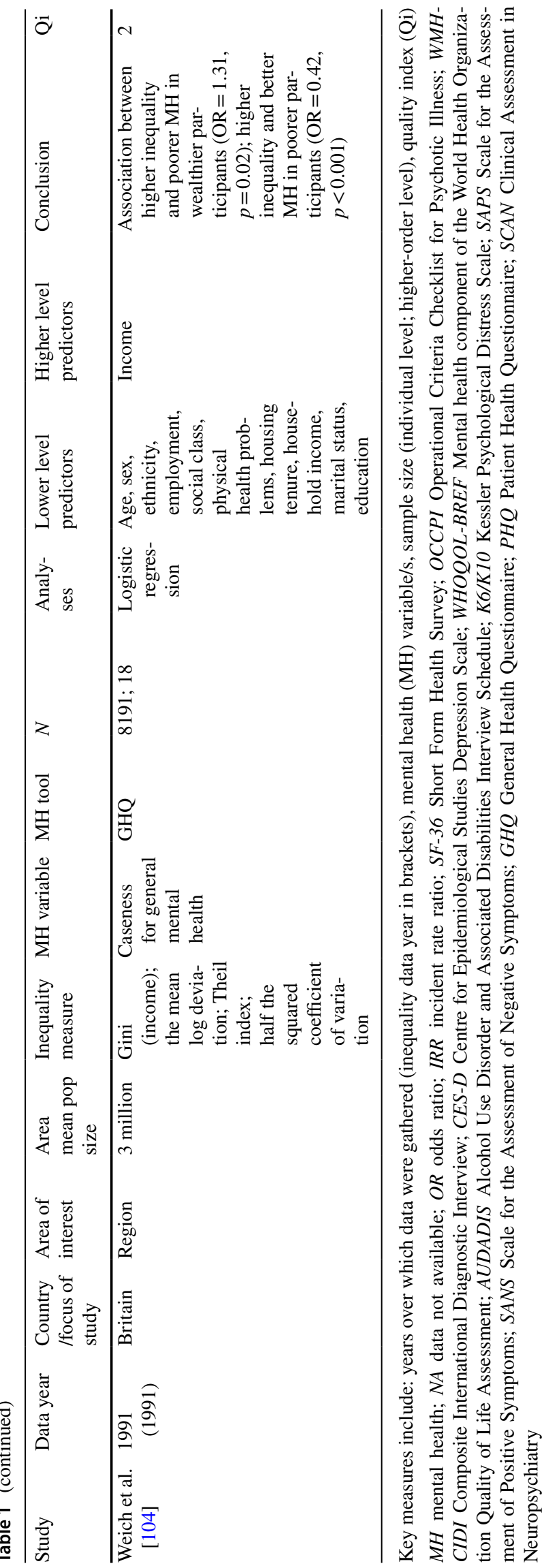

patterns of association differed between mental health conditions, findings were also explored for studies involving different (primary) mental health conditions. Finally, in two further unplanned/post hoc analyses we also explored: (i) where interactions between inequality and absolute deprivation were reported, whether these selectively or disproportionately impacted negatively on the poor or the wealthy, and (ii) whether any findings reported held for low/medium (LMIC) and high income (HIC) countries, as defined by the World Bank Classification system [66].

\section{Results}

A total of 1251 studies were initially identified; 42 of these met criteria for inclusion (Fig. 1). Table 1 presents studies that were retained along with key coded variables. This represented data from 7,744,469 participants residing in 110,247 geographical regions. The largest proportion of studies $(n=17,40.48 \%)$ involved data gathered in the US. With respect to the mental health conditions examined, 19 (45.24\%) investigated depression, 17 (40.48\%) general mental health, 5 psychosis $(11.9 \%)$ and $1(2.38 \%)$ post-traumatic stress disorder (Table 1). The most common measure of inequality used was the Gini coefficient ( $n=34,80.95 \%)$, with four $(9.52 \%)$ using multiple indices and four including single alternative indices.

\section{Findings based on all included studies}

Considering all studies first, $54.76 \%(n=23)$ were partially or wholly supportive of the IIH [67-89], whereas only $11.9 \%$ $(n=5)$ of studies were supportive of the MNH [90-94] (Table 2). In contrast, $33.33 \%(n=14)$ of the studies were unsupportive of either hypothesis [95-108], three of which (21.43\%) showed mixed findings [98, 104, 107] and the remaining 11 (78.57\%) reporting only null findings.

Of 15 studies that were only partially supportive of the $\mathrm{IIH}$, reasons for this included associations only being seen: in low-income participants or deprived wards [67, 68, 86], with respect to certain symptoms or presentations [70, 71, $75,81,85]$, prior to adjustment for covariates $[84,88,89]$, in women [78], at the provincial but not county level [87], at a given time-lag [79]. Finally, one study found that inequality predicted variance in depression symptoms between but not within twin pairs [82].

Of three studies that were only partially supportive of $\mathrm{MNH}$, reasons for this included associations only being seen with respect to a subset of psychosis symptoms [94] or mental health presentations [92]. Finally, one study found that individuals from municipalities with intermediate (but not high) inequality reported lower psychological distress than 
Table 2 Support for the income inequality and mixed neighbourhood hypotheses

\begin{tabular}{|c|c|c|c|c|c|c|c|c|c|}
\hline & & $\begin{array}{l}\text { Wholly sup- } \\
\text { portive of the } \\
\text { IIH }\end{array}$ & $\begin{array}{l}\text { Partially } \\
\text { supportive of } \\
\text { the IIH }\end{array}$ & $\begin{array}{l}\text { Unsupportive } \\
\text { of either }\end{array}$ & $\begin{array}{l}\text { Partially sup- } \\
\text { portive of the } \\
\text { MNH }\end{array}$ & $\begin{array}{l}\text { Wholly sup- } \\
\text { portive of the } \\
\text { MNH }\end{array}$ & Total & $\begin{array}{l}\text { Supportive } \\
\text { of the IIH }\end{array}$ & $\begin{array}{l}\text { Supportive } \\
\text { of the } \mathrm{MNH}\end{array}$ \\
\hline (i) All studies & & $8(19.05)$ & $15(35.71)$ & $14(33.33)$ & $3(7.14)$ & $2(4.76)$ & 42 & $23(54.76)$ & 5 (11.9) \\
\hline $\begin{array}{l}\text { (ii) Higher } \\
\text { quality } \\
\text { studies }\end{array}$ & & $1(6.25)$ & $6(37.5)$ & $7(43.75)$ & $1(6.25)$ & $1(6.25)$ & 16 & $7(43.75)$ & $2(12.5)$ \\
\hline \multirow{3}{*}{$\begin{array}{l}\text { (iii) Con- } \\
\text { trolled for } \\
\text { absolute } \\
\text { deprivation }\end{array}$} & $\begin{array}{l}\text { At lower- } \\
\text { level }\end{array}$ & $6(17.14)$ & $11(31.43)$ & $13(37.14)$ & $3(8.57)$ & $2(5.71)$ & 35 & 17 (48.57) & $5(14.29)$ \\
\hline & $\begin{array}{l}\text { At higher- } \\
\text { level }\end{array}$ & $3(10)$ & $10(33.33)$ & $12(40)$ & $3(10)$ & $2(6.67)$ & 30 & $13(43.33)$ & $5(16.67)$ \\
\hline & At both levels & $2(7.69)$ & $8(30.77)$ & $11(42.31)$ & $3(11.54)$ & $2(7.69)$ & 26 & $10(38.46)$ & $5(19.23)$ \\
\hline \multirow{3}{*}{$\begin{array}{l}\text { (iv) Stratified } \\
\text { by region } \\
\text { mean pop } \\
\text { size }\end{array}$} & $<45,000$ & $1(7.69)$ & $6(46.15)$ & $3(23.08)$ & $2(15.38)$ & $1(7.69)$ & 13 & $7(53.85)$ & $3(23.08)$ \\
\hline & $\geq 45,000$ & $3(23.08)$ & $3(23.08)$ & $7(53.85)$ & $0(0)$ & $0(0)$ & 13 & $6(46.15)$ & $0(0)$ \\
\hline & $\geq 4$ million & $3(23.08)$ & $6(46.15)$ & $2(15.38)$ & $1(7.69)$ & $1(7.69)$ & 13 & $9(69.23)$ & $2(15.38)$ \\
\hline \multirow[t]{2}{*}{$\begin{array}{l}\text { (v) Stratified } \\
\text { by region } \\
\text { type }\end{array}$} & $\begin{array}{l}\text { Counties, } \\
\text { tracts, } \\
\text { parishes (or } \\
\text { similar) }\end{array}$ & $3(14.29)$ & $8(38.1)$ & $7(33.33)$ & $2(9.52)$ & $1(4.76)$ & 21 & $11(52.38)$ & $3(14.29)$ \\
\hline & $\begin{array}{l}\text { States, } \\
\text { regions, } \\
\text { cities (or } \\
\text { similar) }\end{array}$ & $4(22.22)$ & $7(38.89)$ & $5(27.78)$ & $1(5.56)$ & $1(5.56)$ & 18 & $11(61.11)$ & $2(11.11)$ \\
\hline \multirow{3}{*}{$\begin{array}{l}\text { (vi) Stratified } \\
\text { by mental } \\
\text { health con- } \\
\text { dition }\end{array}$} & $\begin{array}{l}\text { General men- } \\
\text { tal health }\end{array}$ & $2(11.76)$ & $5(29.41)$ & $8(47.06)$ & $2(11.76)$ & $0(0)$ & 17 & $7(41.18)$ & $2(11.76)$ \\
\hline & Depression & $5(26.32)$ & $6(31.58)$ & $6(31.58)$ & $0(0)$ & $2(10.53)$ & 19 & $11(57.89)$ & $2(10.53)$ \\
\hline & Psychosis & $1(20)$ & $3(60)$ & $0(0)$ & $1(20)$ & $0(0)$ & 5 & $4(80)$ & $1(20)$ \\
\hline \multirow{2}{*}{$\begin{array}{l}\text { (vii) Stratified } \\
\text { by eco- } \\
\text { nomic status } \\
\text { of country }\end{array}$} & LMIC & $4(36.36)$ & $4(36.36)$ & $3(27.27)$ & $0(0)$ & $0(0)$ & 11 & $8(72.72)$ & $0(0)$ \\
\hline & HIC & $4(12.9)$ & $11(35.48)$ & $11(35.48)$ & $3(9.68)$ & $2(6.45)$ & 31 & 15 (48.39) & $5(16.13)$ \\
\hline
\end{tabular}

The number of studies that were supportive of the Income Inequality Hypothesis (IIH), supportive of the Mixed Neighbourhood Hypothesis $(\mathrm{MNH})$, or else unsupportive of either theory, are presented for: (i) all studies, (ii) higher quality studies only (i.e. those obtaining a maximum score of four on the Quality Index), (iii) studies that controlled for absolute deprivation only (at the lower-level, higher-level and both), (iv) studies stratified by the mean population size of the geographical area of interest $(X<45,000 ; 45,000 \leq X<4$ million; $X \geq 4$ million), (v) studies stratified by region type, (vi) studies stratified by mental health presentation, and (vii) studies stratified by economic status of country from which the data were gathered. For these data, percentages of total studies (row total) are also presented in brackets. In the final two columns partially and wholly supportive data are collapsed for ease of interpretation

LMIC low or medium income countries; HIC high income countries

participants from municipalities with the lowest inequality [93].

Of the three studies that were found to be unsupportive of either hypothesis due to mixed findings, reasons for this included that the sign/nature of the association depended on: the level of neighbourhood deprivation and geographical scale of analysis [98], the wealth of participants [104], or the level of analysis/choice of covariates included [107].

\section{Quality indices and the impact of study quality}

Of the 42 studies included, 5 were deemed to have invalid measure/s (11.9\%), 6 had an inadequate sample size (14.29\%), 16 failed to control for absolute deprivation
(38.1\%) and 12 used non-optimal analyses (28.57\%). The main finding (described above), however, was preserved in the 16 highest quality studies (Qi=4) (Table 2), although the pattern was slightly less pronounced: $43.75 \%$ supported the IIH $[67,75,77,78,85,87,88]$ and $12.5 \%$ supported the MNH [90, 94].

\section{Impact of absolute deprivation as a covariate}

A similar pattern emerged when we restricted analyses to studies that controlled for absolute levels of deprivation, at either lower-order, higher-order, or both levels (Table 2). Twenty-six studies controlled for absolute deprivation at both levels, with twice as many studies supporting the IIH 
$(n=10,40 \%)[67,73,75,77,78,81,85-88]$ compared with the MNH $(n=5,20 \%)$ [90-94].

\section{Effects of geographical scale}

There was little to suggest that the association between inequality and mental health was dependent on geographical scale, irrespective of whether this was defined by region mean population size or region type. Thus, across these analyses $46.15-69.23 \%$ of studies supported the IIH whereas only $0-23.08 \%$ of studies supported the MNH. It is worth noting, however, that in both sets of analyses the highest support for the IIH was found at the largest geographical scale.

\section{Patterns for different mental health conditions}

There was stronger support for the IIH than there was for the $\mathrm{MNH}$, across all mental health categories examined: general mental health ( $41.18 \%$ vs. $11.76 \%)$, depression $(57.89 \%$ vs. $10.53 \%$ ) and psychosis ( $80 \%$ vs. $20 \%$ ), although the pattern was most pronounced for psychosis.

\section{Role of absolute deprivation}

Twenty of the 42 studies included tested for interactions between inequality and absolute deprivation, either by adding cross-level interaction terms or stratification of data by indices of deprivation or wealth. Of these, 14 found evidence of an interaction. Eight of these indicated that the poor fared worse; i.e. where associations between higher inequality and poorer mental health were reported these were more pronounced amongst the deprived, or where associations between higher inequality and better mental health were reported, these were specific to wealthy areas $[67,68,74,80$, 83, 84, 86, 98]. Conversely, six indicated that the rich fared worse, such that they were linked to more positive and/or less negative effects of inequality [87, 89, 90, 92, 104, 107].

\section{Effects of country-level economic status}

Eleven studies included data from LMICs and 31 included data from HICs. Whilst both showed higher support for the IIH than the MNH, the pattern was much more pronounced in the LMICs $(72.72 \%$ vs. $0 \%)$ than in the HICs $(48.39 \%$ vs. $16.13 \%)$.

\section{Discussion}

Based on a systematic review of the literature we consistently found greater support for the IIH over the MNH. This pattern was not dependent on study quality, spatial scale, adjustment for absolute deprivation, nor country income level. However, a high proportion of studies supported neither hypothesis, reporting no significant association between inequality and mental health, or else mixed patterns of associations. To explain such a high level of null findings one might posit two possible explanations. First, that findings supportive of the IIH have arisen purely by chance, but are over-represented in the literature $[109,110]$. Second, that the association is real, but statistically small and/or potentially dependent on other moderating variables. Consistent with the latter interpretation, a parallel modest association has also been documented between higher inequality and poorer physical health [27], with overlapping mechanisms having been proposed for mental and physical health [31]. Nonetheless, in reviewing the extant literature we identified a number of limitations, most notably a lack of adequate control for absolute deprivation (at the lower and higher-order levels) and the use of suboptimal (i.e. single-level) analyses.

Considering more specific predictions of the IIH, the findings reported are broadly consistent with the notion that the effects of inequality are not limited to poorer members of society [11]. The association between higher inequality and poorer mental health persisted after controlling for absolute deprivation and was evidenced in HICs and LMICs. In addition, where studies investigated an interaction between inequality and absolute deprivation, a roughly equal proportion indicated that the poor or the rich were negatively impacted. Assuming a casual association (more on this below), this is a crucial finding with implications for the potential scale of impact and ways of incentivising change, since it implies that all segments of society stand to be affected by the negative effects of inequality, and by inference, stand to gain by addressing the issue.

With respect to geographical scale $[55,96]$, the reported association persisted across all spatial scales studied, although it was somewhat more pronounced at higher spatial scales. Drawing on the SAH, these findings are consistent with social comparison [111] and social rank [112] theories, which posit that the negative effects of social comparisons operate across multiple reference groups and spatial scales, including the local $[113,114]$. Such scaling effects may also be supported by the growing ubiquity of social/digital tools such as social network sites [115], which have arguably transformed the potential scope and scale of such comparative processes [116].

Whilst the IIH makes no explicit predictions about the specificity of effects on different mental health conditions, stratification by mental health suggested that the association between inequality and mental health may be particularly pronounced in psychosis (although the sample size of studies was very small). It is unclear why this might be the case; however, one tentative hypothesis is that the lack of social integration and trust that arguably characterises unequal communities (according to the $\mathrm{SCH}$ and $\mathrm{SAH}$ ) may 
be particularly conducive to experiences of paranoia, a core symptom of psychosis [117]. These findings, if found to hold with further research, have potential implications for the commissioning and delivery of psychosis services (more on this below).

With respect to the limitations of this review, no measure of sampling bias was included. Some studies used convenience sampling, and others purposely over-sampled specific ethnic groups or geographical regions so that conclusions could be drawn about low incidence groups (see Supplementary Information 3). Nonetheless, this may limit the generalizability of findings. Further, whilst the decision was based on firm theoretical grounds [60-62], the lack of integration of effect sizes across studies means that the real-world significance of the findings are difficult to gauge. Finally, no conclusions can be drawn about the direction of causality or underlying mechanisms. Whilst these were not the foci of the review, in the absence of such information the findings we report are merely consistent with the IIH. Nonetheless, it is worth noting that in a review of the literature into the association between inequality and health (more generally), the authors concluded that there was good support for the main criteria used to test for causality within a causal epidemiological framework, i.e. temporality, biological plausibility, consistency and lack of alternative explanations [118].

If we accept the proposed notion of a casual association between inequality and mental health, several important implications emerge from our findings. Most fundamentally, they suggest that rising levels of inequality may drive increases in the incidence of mental health disorders, and arguably as a consequence, that inequality (alongside poverty and other environmental factors) should be placed at the centre of psychiatry and applied psychology [5]. For example, national guidelines for Early Intervention Psychosis services in the UK [119] state that commissioning "should be underpinned by estimated local incidence of psychosis, derived to incorporate a range of demographic features such as ethnicity, age, population density and deprivation" (p. 6), and to this we would add inequality as a further important factor for consideration.

The findings also raise the possibility that national health expenditure, which has traditionally focused on the development and provision of mental health services that work with the individual to target symptom reduction [120], may need to include parallel investments into a wider range of services as part of a more systemic, preventative approach if they are to be effective [121, 122]. For example, Marmot [123] has argued for the importance of focusing on "early child development and education, work environments, building healthy communities and supporting active social engagement of older people" in overcoming the effects of social inequality on health (p. 153). Conversely, we would suggest that the findings strongly call into question the wisdom of implementing mixed tenure policies that aim to create mixed communities, including with respect to income [124].

Relatedly, an argument might also be made for tackling inequality more directly, i.e. as primary causal/upstream factor, as part of government policy. Thus, many academics, including economists [125] and epidemiologists [123], have argued that trends for rising inequality can be reversed through targeted changes in social policy without sacrificing overall economic growth [126]. Proven tools in this regard include progressive taxation and focused expenditure aimed at improving education and reducing hunger and poverty $[127,128]$. Relatedly, our finding that LMICs may be particularly susceptible to the negative effects of income inequality, suggests that international development and aid programmes, which have traditionally focused on increasing economic growth, may benefit from a broader remit that includes working to reduce economic inequality [129], a perspective that is reflected in the UN Sustainable Development Goals (Goal 10: 'Reduce inequality within and among countries', p.14) [130].

\section{Conclusions}

This systematic review highlights an association between higher levels of income inequality and poorer adult mental health at the subnational level. Whilst the review did not attempt to identify the mechanisms or direction of this association, the conclusions drawn reinforce the importance of inequality in potentially contributing to mental health problems in the population. Further research into the causal strength of such environmental predictors on psychological distress is urgently required so we can assess the potential value of implementing interventions to ameliorate the negative effects of inequality. This research effort now needs to gather pace, and is we would argue, underpinned by an ethical imperative. In a recent report entitled 'Britain in the 2020s' the Institute for Public Policy Research [131] predicted that inequality will "surge" over the course of the decade (p. 12), with the income of the rich forecasted to rise 11 times faster than the incomes of the poor, and an extra 3.6 million predicted to fall into poverty within this time-frame.

Supplementary Information The online version contains supplementary material available at https://doi.org/10.1007/s00127-021-02159-w.

Author contributions MST: conceptualisation, methodology, formal analysis, data curation, writing, (original draft); $\mathrm{VH}$ : supervision, conceptualisation, methodology, writing (review and editing); FW: formal analysis, data curation, writing (review and editing); JK: formal analysis, writing (review and editing).

Funding None. JBK is supported by the National Institute for Health Research University College London Hospitals Biomedical Research Centre. 
Availability of data and material Not applicable.

Code availability Not applicable.

\section{Declarations}

\section{Conflict of interest None.}

Open Access This article is licensed under a Creative Commons Attribution 4.0 International License, which permits use, sharing, adaptation, distribution and reproduction in any medium or format, as long as you give appropriate credit to the original author(s) and the source, provide a link to the Creative Commons licence, and indicate if changes were made. The images or other third party material in this article are included in the article's Creative Commons licence, unless indicated otherwise in a credit line to the material. If material is not included in the article's Creative Commons licence and your intended use is not permitted by statutory regulation or exceeds the permitted use, you will need to obtain permission directly from the copyright holder. To view a copy of this licence, visit http://creativecommons.org/licenses/by/4.0/.

\section{References}

1. Whiteford HA, Degenhardt L, Rehm J et al (2013) Global burden of disease attributable to mental and substance use disorders: findings from the Global Burden of Disease Study 2010. Lancet 382:1575-1586. https://doi.org/10.1016/S0140-6736(13)61611-6

2. Layard R (2015) A new priority for mental health. London School of Economic Sciences, London

3. Clark DM (2011) Implementing NICE guidelines for the psychological treatment of depression and anxiety disorders: the IAPT experience. Int Rev Psychiatry 23:318-327. https://doi.org/10. 3109/09540261.2011.606803

4. Harper D (2016) Beyond individual therapy. Psychologist 29:440-444

5. Byrne P, James A (2020) Placing poverty-inequality at the centre of psychiatry. BJ Psych Bull 44:187-190. https://doi.org/10. 1192/bjb.2020.85

6. Dean CE (2017) Social inequality, scientific inequality, and the future of mental illness. Philos Ethics Human Med 12:1-12

7. Smith JP (1999) Healthy bodies and thick wallets: the dual relation between health and economic status. J Econ Perspect 13:145-166. https://doi.org/10.1257/jep.13.2.145

8. World Bank (1993) World Development Report 1993-investing in health. The World Bank

9. Wilkinson RG (1999) The epidemiological transition: from material scarcity to social disadvantage? In: Kawachi I, Kennedy BP, Wilkinson RG (eds) The society and population health reader, vol 1. Income Inequality and Health. New York Press, New York, NY, pp 36-46

10. European Values Survey Group WVSA (2002) European and world values surveys integrated data file, 1999-2002, release I

11. Wilkinson RG, Pickett K (2009) The Spirit level. The Penguin Group, London

12. Boarini R, D'Ercole MM (2013) Going beyond GDP: an OECD perspective. Fisc Stud 34:289-314. https://doi.org/10.1111/j. 1475-5890.2013.12007.x

13. McDonough P, Duncan GJ, Williams D, House J (1997) Income dynamics and adult mortality in the United States, 1972 through 1989. Am J Public Health 87:1476-1483

14. World Health Organisation (2000) Cross-national comparisons of the prevalences and correlates of mental disorders. WHO
International Consortium in Psychiatric Epidemiology. Bull World Health Organ 78:413-426

15. Muntaner C, Eaton WW, Miech R, O'Campo P (2004) Socioeconomic position and major mental disorders. Epidemiol Rev 26:53-62. https://doi.org/10.1093/epirev/mxh001

16. Murali V, Oyebode F (2004) Poverty, social inequality and mental health. Adv Psychiatr Treat 10:216-224

17. Pampel FC, Krueger PM, Denney JT (2010) Socioeconomic disparities in health behaviors. Annu Rev Sociol 36:349-370. https://doi.org/10.1146/annurev.soc.012809.102529

18. Kragten N, Rözer J (2017) The income inequality hypothesis revisited: assessing the hypothesis using four methodological approaches. Soc Indic Res 131:1015-1033. https://doi.org/10. 1007/s11205-016-1283-8

19. De Maio FG (2007) Income inequality measures. J Epidemiol Community Health 61:849-852. https://doi.org/10.1136/jech. 2006.052969

20. Pickett KE, Kelly S, Brunner E et al (2005) Wider income gaps, wider waistbands? An ecological study of obesity and income inequality. J Epidemiol Commun Health 59:670-674. https://doi. org/10.1136/jech.2004.028795

21. Wilkinson RG (1990) Income distribution and mortality: a "natural" experiment. Soc Heal Illn 12:391-412. https://doi.org/10. 1111/1467-9566.ep11340405

22. Wilkinson RG, Pickett KE (2009) Income inequality and social dysfunction. Annu Rev Sociol 35:493-511

23. Wilkinson RG, Pickett KE (2007) The problems of relative deprivation: why some societies do better than others. Soc Sci Med 65:1965-1978

24. Saunders P (2010) Beware false prophets-equality, the good society and the spirit level. Policy Exchange, London

25. Snowdon JC (2010) The spirit level delusion: fact-checking the left's new theory of everything. Democracy Institute/Little Dice

26. Wilkinson RG, Pickett KE (2017) Professors Richard Wilkinson and Kate Pickett, authors of The Spirit Level, reply to critics. https://www.equalitytrust.org.uk/sites/all/themes/equalitytrust/ images/response-to-snowdon.pdf

27. Kondo N, Sembajwe G, Kawachi I et al (2009) Income inequality, mortality, and self rated health: meta-analysis of multilevel studies. BMJ 339:b4471

28. Macinko JA, Shi L, Starfield B, Wulu JT (2003) Income inequality and health: a critical review of the literature. Med Care Res Rev 60:407-452. https://doi.org/10.1177/1077558703257169

29. Rowlingson K (2011) Does income inequality cause health and social problems?

30. Torre R, Myrskylä M (2014) Income inequality and population health: an analysis of panel data for 21 developed countries, 1975-2006. Popul Stud (NY) 68:1-13. https://doi.org/10.1080/ 00324728.2013 .856457

31. Zimmerman FJ, Bell JF (2006) Income inequality and physical and mental health: testing associations consistent with proposed causal pathways. J Epidemiol Commun Health 60:513-521

32. Kawachi I, Kennedy BP (1997) The relationship of income inequality to mortality: does the choice of indicator matter? Soc Sci Med 45:1121-1127

33. Layte R (2012) The association between income inequality and mental health: testing status anxiety, social capital, and neomaterialist explanations. Eur Sociol Rev 28:498-511. https:// doi.org/10.1093/esr/jcr012

34. Takahashi T, Ikeda K, Ishikawa M et al (2005) Interpersonal trust and social stress-induced cortisol elevation. NeuroReport 16:197-199

35. Coleman JS (1988) Social capital in the creation of human capital. Am J Sociol 94:S95-S120. https://doi.org/10.1086/228943 
36. Pham-Kanter G (2009) Social comparisons and health: can having richer friends and neighbors make you sick? Soc Sci Med 69:335-344. https://doi.org/10.1016/j.socscimed.2009.05.017

37. Smith HJ, Pettigrew TF, Pippin GM, Bialosiewicz S (2012) Relative deprivation: a theoretical and meta-analytic review. Pers Soc Psychol Rev 16:203-232. https://doi.org/10.1177/1088868311 430825

38. Kaplan GA, Pamuk ER, Lynch JW et al (1996) Inequality in income and mortality in the United States: analysis of mortality and potential pathways. BMJ 312:999-1003

39. Dunn JR, Burgess B, Ross NA (2005) Income distribution, public services expenditures, and all cause mortality in US States. J Epidemiol Commun Health 59:768-774. https://doi.org/10.1136/ jech.2004.030361

40. Ronzio CR, Pamuk E, Squires GD (2004) The politics of preventable deaths: local spending, income inequality, and premature mortality in US cities. J Epidemiol Commun Health 58:175-179. https://doi.org/10.1136/JECH.2003.008672

41. Smith GD (1996) Income inequality and mortality: why are they related? BMJ 312:987-988

42. Manley D, VanHam M, Doherty J (2012) Social mixing as a cure for negative neighbourhood effects: evidence based policy or urban myth? In: Bridge G, Butler T, Lees L (eds) Mixed communities: gentrification by stealth? The Policy Press, Bristol, pp $1-17$

43. Musterd S, Andersson R (2005) Housing mix, social mix, and social opportunities. Urban Aff Rev 40:761-790. https://doi.org/ 10.1177/1078087405276006

44. Ostendorf W, Musterd S, De Vos S (2001) Social mix and the neighbourhood effect. Policy ambitions and empirical evidence. Hous Stud 16:371-380. https://doi.org/10.1080/0267303012 0049724

45. Popkin SJ, Katz B, Cunningham MK et al (2004) A decade of HOPE VI: research findings and policy challenges. Urban Institute, Washington, DC

46. Cheshire P (2012) Are mixed community policies evidence based? A review of the research on neighbourhood effects. Neighbourhood effects research: new perspectives. Springer, Netherlands, Dordrecht, pp 267-294

47. Monk S, Clarke A, Tang CPY (2011) Mixed communities literature review. Scottish Government, Edinburgh

48. Levy DK, McDade Z, Dumlao K (2010) Effects from living in mixed-income communities for low-income families-a review of the literature. Urban Institute, Washington, DC

49. Wilkinson R, Pickett K (2018) The inner level-how more equal societies reduce stress, restore sanity and improve everyone's wellbeing, first. Penguin Random House, St Ives

50. Burns JK, Tomita A, Kapadia AS (2014) Income inequality and schizophrenia: Increased schizophrenia incidence in countries with high levels of income inequality. Int J Soc Psychiatry 60:185-196. https://doi.org/10.1177/0020764013481426

51. Patel V, Burns JK, Dhingra $M$ et al (2018) Income inequality and depression: a systematic review and meta-analysis of the association and a scoping review of mechanisms. World Psychiatry 17:76-89

52. Ribeiro WS, Bauer A, Andrade MCR et al (2017) Income inequality and mental illness-related morbidity and resilience: a systematic review and meta-analysis. Lancet Psychiatry 4:554-562. https://doi.org/10.1016/S2215-0366(17)30159-1

53. Lynch J, Smith GD, Harper S et al (2004) Is income inequality a determinant of population health? Part 1. A. systematic review. Milbank Q 82:5-99

54. Fiscella K, Franks P (1999) Poverty or income inequality as a predictor of mortality: longitudinal cohort study. In: Kawachi I, Kennedy BP, Wilkinson RG (eds) The society and population health reader, vol 1. Income inequality and health. New York Press, New York, NY, pp 105-111

55. Pickett KE, Wilkinson RG (2010) Inequality: an underacknowledged source of mental illness and distress. Br J Psychiatry 197:426-428

56. Wilkinson RG, Pickett KE (2006) Income inequality and population health: a review and explanation of the evidence. Soc Sci Med 62:1768-1784. https://doi.org/10.1016/j.socscimed.2005. 08.036

57. Tibber MS (2017) Part 1 of Thesis: A systematic review of the association between income inequality and adult mental health at the subnational level. University College, London

58. Tibber MS, Walji F, Huddy VC (2020) Update of an unpublished systematic review of the association between income inequality and adult mental health at the subnational level. In: PROSPERO_-Int. Prospect. Regist. Syst. Rev. https://www.crd.york. ac.uk/prospero/display_record.php?ID=CRD42020181507

59. Moher D, Liberati A, Tetzlaff J, Altman DG (2009) Preferred reporting items for systematic reviews and meta-analyses: the PRISMA statement. BMJ 339:332-336

60. Cooper H (2003) Psychological bulletin: editorial. Psychol Bull 129:3-9. https://doi.org/10.1037/0033-2909.129.1.3

61. Hinshaw SP (2009) Editorial. Psychol Bull 135:511-515. https:// doi.org/10.1037/a0014869

62. Sharpe D (1997) Of apples and oranges, file drawers and garbage: why validity issues in meta-analysis will not go away. Clin Psychol Rev 17:881-901

63. Light R, Smith P (1971) Accumulating evidence: procedures for resolving contradictions among different research studies. Harv Educ Rev 41:429-471

64. Lincoln T, Simon-Levine D, Smith J et al (2015) Prevalence and predictors of mental/emotional distress among HIV+ jail detainees at enrollment in an observational study. J Correct Heal Care 21:125-139

65. Uphoff EP, Pickett KE, Cabieses B et al (2013) A systematic review of the relationships between social capital and socioeconomic inequalities in health: a contribution to understanding the psychosocial pathway of health inequalities. Int J Equity Health 12:54. https://doi.org/10.1186/1475-9276-12-54

66. Charts Bin statistics collector team Country Income Groups (World Bank Classification). In: ChartsBin.com. http://chartsbin. com/view/2438

67. Ahern J, Galea S (2006) Social context and depression after a disaster: the role of income inequality. J Epidemiol Commun Health 60:766-770

68. Boydell J, van Os J, McKenzie K, Murray RM (2004) The association of inequality with the incidence of schizophrenia - an ecological study. Soc Psychiatry Psychiatr Epidemiol 39:597599. https://doi.org/10.1007/s00127-004-0789-6

69. Burns JK, Esterhuizen T (2008) Poverty, inequality and the treated incidence of first-episode psychosis: an ecological study from South Africa. Soc Psychiatry Psychiatr Epidemiol 43:331335. https://doi.org/10.1007/s00127-008-0308-2

70. Chiavegatto Filho ADP, Kawachi I, Wang YP et al (2013) Does income inequality get under the skin? A multilevel analysis of depression, anxiety and mental disorders in Sao Paulo, Brazil. J Epidemiol Commun Health 67:966-972. https://doi.org/10.1136/ jech-2013-202626

71. Choi H, Burgard S, Elo IT, Heisler M (2015) Are older adults living in more equal counties healthier than older adults living in more unequal counties? A propensity score matching approach. Soc Sci Med 141:82-90

72. Fiscella K, Franks P (2000) Individual income, income inequality, health, and mortality: what are the relationships? Health Serv Res 35:307-318 
73. Hanandita W, Tampubolon G (2014) Does poverty reduce mental health? An instrumental variable analysis. Soc Sci Med 113:59-67

74. Kahn RS, Wise PH, Kennedy BP, Kawachi I (2000) State income inequality, household income, and maternal mental and physical health: cross sectional national survey. BMJ Br Med J 321:1311-1315

75. Kirkbride JB, Jones PB, Ullrich S, Coid JW (2014) Social deprivation, inequality, and the neighborhood-level incidence of psychotic syndromes in East London. Schizophr Bull 40:169-180

76. Messias E, Eaton WW, Grooms AN (2011) Economic grand rounds: income inequality and depression prevalence across the United States: an ecological study. Psychiatr Serv 62:710-712

77. Muramatsu N (2003) County-level income inequality and depression among older Americans. Health Serv Res 38:1863-1883

78. Pabayo R, Kawachi I, Gilman SE (2014) Income inequality among American states and the incidence of major depression. J Epidemiol Commun Health 68:110-115

79. Bocoum I, Tohon AB, Rukundo R et al (2019) Effect of income inequality on health in Quebec: new insights from panel data. Sustain. https://doi.org/10.3390/su11205700

80. Burns JK, Tomita A, Lund C (2017) Income inequality widens the existing income-related disparity in depression risk in postapartheid South Africa: evidence from a nationally representative panel study. Heal Place 45:10-16. https://doi.org/10.1016/j.healt hplace.2017.02.005

81. Chen R, Kessler RC, Sadikova E et al (2019) Racial and ethnic differences in individual-level and area-based socioeconomic status and 12-month DSM-IV mental disorders. J Psychiatr Res 119:48-59. https://doi.org/10.1016/j.jpsychires.2019.09.006

82. Cohen-Cline H, Beresford SAA, Barrington WE et al (2018) Associations between neighbourhood characteristics and depression: a twin study. J Epidemiol Commun Health 72:202-207. https://doi.org/10.1136/jech-2017-209453

83. Du H, King RB, Chi P (2019) Income inequality is detrimental to long-term well-being: a large-scale longitudinal investigation in China. Soc Sci Med 232:120-128. https://doi.org/10.1016/j. socscimed.2019.04.043

84. Lin Y, Zhang Q, Chen W, Ling L (2017) The social income inequality, social integration and health status of internal migrants in China. Int J Equity Health. https://doi.org/10.1186/ s12939-017-0640-9

85. Pabayo R, Fuller D, Goldstein RB et al (2017) Income inequality among American states and the conditional risk of post-traumatic stress disorder. Soc Psychiatry Psychiatr Epidemiol 52:11951204. https://doi.org/10.1007/s00127-017-1413-x

86. Sommet N, Morselli D, Spini D (2018) Income inequality affects the psychological health of only the people facing scarcity. Psychol Sci 29:1911-1921. https://doi.org/10.1177/0956797618 798620

87. Ding R, Zhang L, He P et al (2020) Income, income inequality and schizophrenia in China: a population-based multilevel analysis. J Epidemiol Commun Health 74:719-725. https://doi. org/10.1136/jech-2019-213049

88. Dev S, Kim D (2020) State-level income inequality and countylevel social capital in relation to individual-level depression in middle-aged adults: a lagged multilevel study. Int J Environ Res Public Health 17:1-12. https://doi.org/10.3390/ijerph17155386

89. Fan VS, Mahadevan R, Leung J (2020) Effect of income inequality, community infrastructure and individual stressors on adult depression. Health Promot Int. https://doi.org/10.1093/heapro/ daaa036

90. Marshall A, Jivraj S, Nazroo J et al (2014) Does the level of wealth inequality within an area influence the prevalence of depression amongst older people? Health Place 27:194-204. https://doi.org/10.1016/j.healthplace.2014.02.012
91. Haithcoat TL, Avery EE, Bowers KA et al (2019) Income inequality and health: expanding our understanding of state-level effects by using a geospatial big data approach. Soc Sci Comput Rev. https://doi.org/10.1177/0894439319872991

92. Matthew P, Brodersen DM (2018) Income inequality and health outcomes in the United States: an empirical analysis. Soc Sci J 55:432-442. https://doi.org/10.1016/j.soscij.2018.05.001

93. Sebastián MS, Mosquera PA, Gustafsson PE (2018) Whose income is more important: mine, yours or ours? Income inequality and mental health in northern Sweden. Eur J Public Health 28:1056-1061. https://doi.org/10.1093/eurpub/cky110

94. Tibber MS, Kirkbride JB, Mutsatsa S et al (2019) Are socioenvironmental factors associated with psychotic symptoms in people with first-episode psychosis? A cross-sectional study of a West London clinical sample. BMJ Open 9:30448. https://doi.org/10. 1136/bmjopen-2019-030448

95. Bechtel L, Lordan G, Rao DSP (2012) Income inequality and mental health-empirical evidence from Australia. Health Econ 21:4-17

96. Drukker M, Feron FJM, van Os J (2004) Income inequality at neighbourhood level and quality of life a contextual analysis. Soc Psychiatry Psychiatr Epidemiol 39:457-463

97. Fernandez-Nino JA, Manrique-Espinoza BS, Bojorquez-Chapela I, Salinas-Rodriguez A (2014) Income inequality, socioeconomic deprivation and depressive symptoms among older adults in Mexico. PLoS ONE 9:e108127

98. Fone D, Greene G, Farewell D et al (2013) Common mental disorders, neighbourhood income inequality and income deprivation: small-area multilevel analysis. Br J Psychiatry 202:286-293

99. Gresenz CR, Sturm R, Tang L (2001) Income and mental health: unraveling community and individual level relationships. J Ment Health Policy Econ 4:197-203

100. Henderson C, Liu X, Diez Roux AV et al (2004) The effects of US state income inequality and alcohol policies on symptoms of depression and alcohol dependence. Soc Sci Med 58:565-575

101. Lee EW, Park JH (2015) Individual and socioeconomic contextual effects on depressive symptom in Korea: multilevel analysis of cross-sectional nationwide survey. J Korean Med Sci 30:186193. https://doi.org/10.3346/jkms.2015.30.2.186

102. Peterson LE, Tsai AC, Petterson S, Litaker DG (2009) Ruralurban comparison of contextual associations with self-reported mental health status. Health Place 15:125-132. https://doi.org/ 10.1016/j.healthplace.2008.03.001

103. Sturm R, Gresenz CR (2002) Relations of income inequality and family income to chronic medical conditions and mental health disorders: National survey. BMJ Br Med J 324:20-22

104. Weich S, Lewis G, Jenkins SP (2001) Income inequality and the prevalence of common mental disorders in Britain. Br J Psychiatry $178: 222-227$

105. Adjaye-Gbewonyo K, Avendano M, Subramanian SV, Kawachi I (2016) Income inequality and depressive symptoms in South Africa: a longitudinal analysis of the National Income Dynamics Study. Health Place 42:37-46

106. Bisung E, Kangmennaang J, Luginaah I (2018) Neighborhood structural differences and women's mental health: an empirical study in Accra, Ghana. Qual Life Res 27:661-671. https://doi. org/10.1007/s11136-017-1731-1

107. Erdem Ö, Van Lenthe FJ, Burdorf A (2019) Income inequality and psychological distress at neighbourhood and municipality level: an analysis in the Netherlands. Heal Place 56:1-8. https:// doi.org/10.1016/j.healthplace.2018.12.011

108. Fujita M, Nagashima K, Takahashi S, Hata A (2019) Inequality within a community at the neighborhood level and the incidence of mood disorders in Japan: a multilevel analysis. Soc Psychiatry Psychiatr Epidemiol 54:1125-1131. https://doi.org/10.1007/ s00127-019-01687-w 
109. Rosenthal R (1979) The file drawer problem and tolerance for null results. Psychol Bull 86:638-641. https://doi.org/10.1037/ 0033-2909.86.3.638

110. Nieuwenhuis J (2016) Publication bias in the neighbourhood effects literature. Geoforum 70:89-92. https://doi.org/10.1016/j. geoforum.2016.02.017

111. Festinger L (1954) A theory of social comparison processes. Hum Relat 7:117-140

112. Gilbert P (2000) The relationship of shame, social anxiety and depression: the role of the evaluation of social rank. Clin Psychol Psychother 7:174-189. https://doi.org/10.1002/10990879(200007)7:3\%3c174::AID-CPP236\%3e3.0.CO;2-U

113. Clark A, Senik C (2010) Who compares to whom? The anatomy of income comparisons in Europe. Econ J 120:573-594. https:// doi.org/10.1111/j.1468-0297.2010.02359.x

114. Goerke L, Pannenberg M (2013) Direct evidence on income comparisons and subjective well-being. SSRN Electron J. https://doi. org/10.2139/ssrn.2253840

115. Verduyn P, Gugushvili N, Massar K et al (2020) Social comparison on social networking sites. Curr Opin Psychol 36:32-37

116. Nesi J, Choukas-Bradley S, Prinstein MJ (2018) Transformation of adolescent peer relations in the social media context: part 2-application to peer group processes and future directions for research. Clin Child Fam Psychol Rev 21:295-319

117. Cromby J, Harper D (2005) Paranoia and social inequality. Clin Psychol Forum 153:17-21

118. Pickett KE, Wilkinson RG (2015) Income inequality and health: a causal review. Soc Sci Med 128:316-326

119. NICE (2016) Implementing the early intervention in psychosis access and waiting time standard: guidance

120. Clark A, Fleche S, Layard R et al (2016) Origins of happiness: evidence and policy implications. London School of economics and Political Sciences, London
121. Dahlgren G, Whitehead M (1991) Policies and strategies to promote social equity in health-background document to WHO Strategy paper for Europe. WHO, Stockholm

122. World Health Organisation (2004) Prevention of mental disorders: effective interventions and policy options—summary report. WHO, Geneva

123. Marmot M (2004) Status syndrome. Significance 1:150-154. https://doi.org/10.1111/j.1740-9713.2004.00058.x

124. Sautkina E, Bond L, Kearns A (2012) Housing studies mixed evidence on mixed tenure effects: findings from a systematic review of UK Studies, 1995-2009. Hous Stud 27:748-782. https://doi. org/10.1080/02673037.2012.714461

125. Stiglitz J (2013) The price of inequality, 2nd edn. Penguin Books, London

126. Cingano $\mathrm{F}$ (2014) Trends in income inequality and its impact on economic growth. OECD Publishing, Paris

127. OECD (2015) Inequality-improving policies to reduce inequality and poverty. OECD, Paris

128. Keeley B (2015) How can governments respond to income inequality? Income inequality-the gap between rich and poor. OECD insights. OECD Publishing, Paris, pp 79-104

129. Ward JL, Viner RM (2017) The impact of income inequality and national wealth on child and adolescent mortality in low and middle-income countries. BMC Public Health 17:429. https:// doi.org/10.1186/s12889-017-4310-Z

130. United Nations (2015) General assembly resolution 70/1. Transforming our world: the 2030 agenda for sustainable development

131. Lawrence M (2016) Future proof-Britain in the 2020s. IPPR, London 